\title{
Syk Inhibitor Attenuates Polymicrobial Sepsis in FcgRllb-Deficient Lupus Mouse Model, the Impact of Lupus Characteristics in Sepsis
}

\author{
Jiraphorn Issara-Amphorn ${ }^{a, b}$ Wiwat Chancharoenthana ${ }^{c}$

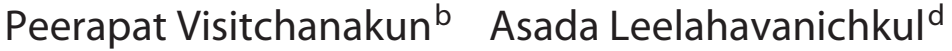 \\ a Medical Microbiology, Interdisciplinary and International Program, Graduate School, Chulalongkorn University, \\ Bangkok, Thailand; 'Department of Microbiology, Faculty of Medicine, Chulalongkorn University, Bangkok, \\ Thailand; 'Nephrology Research Unit, Department of Clinical Tropical Medicine, Faculty of Tropical Medicine, \\ Mahidol University, Bangkok, Thailand; ' Translational Research in Inflammation and Immunology Research Unit \\ (TRIRU), Department of Microbiology, Chulalongkorn University, Bangkok, Thailand
}

\section{Keywords}

FcgRllb-deficient mice - Systemic lupus erythematosus ·

Endotoxin - Gut leakage - Spleen tyrosine kinase · Sepsis

\begin{abstract}
The impact of spleen tyrosine kinase (Syk) signaling might be prominent in lupus because (i) Syk is a shared downstream signaling molecule among circulating immune complex, LPS, and ( $1 \rightarrow 3$ )- $\beta$-D-glucan (BG), and (ii) all of these factors are detectable in the serum of Fc gamma receptor Ilbdeficient (FcgRIlb ${ }^{-1-}$ ) mice with sepsis. As a proof of concept study, we activated macrophages with BG combined with LPS (BG + LPS). We found that BG + LPS predominantly upregulated Syk expression and proinflammatory cytokines in $\mathrm{FcgRIlb}^{-/}$macrophages compared with wild-type (WT) macrophages. Syk inhibition downregulated several inflammatory pathways in FcgRIIb-/- macrophages activated with BG + LPS, as determined by RNA sequencing analysis, suggesting the potential anti-inflammatory impact of Syk inhibitors in lupus. Indeed, administration of a Syk inhibitor prior to cecal ligation and puncture (CLP) sepsis in $\mathrm{FcgRIIb}^{-/-}$mice reduced baseline lupus-induced proinflammatory cytokines and attenuated sepsis severity as evaluated by mortality,
\end{abstract}

karger@karger.com www.karger.com/jin

Karger $\stackrel{\text { ' }}{=}$

马OPEN ACCESS
(C) 2020 The Author(s)

Published by S. Karger AG, Basel

This article is licensed under the Creative Commons AttributionNonCommercial-NoDerivatives 4.0 International License (CC BYNC-ND) (http://www.karger.com/Services/OpenAccessLicense) Usage and distribution for commercial purposes as well as any distribution of modified material requires written permission. organ injury, serum LPS, and post-sepsis serum cytokines. In conclusion, it was easier to induce Syk expression in $\mathrm{FcgRIIb}^{-1-}$ macrophages than in WT macrophages. This might be because of the loss of inhibitory signaling, which might be responsible for prominent Syk abundance in the spleens of 40-week-old FcgRIlb ${ }^{-1-}$ mice and the potent effect of Syk inhibitor in lupus mice compared with WT.

(c) 2020 The Author(s).

Published by S. Karger AG, Basel

\section{Introduction}

Systemic lupus erythematosus is associated with functional defects of Fc gamma receptor IIb (FcgRIIb), the only inhibitory receptor among the FcgR family [1-3], and FcgRIIb dysfunction polymorphism is high in the Asian population [4]; therefore, FcgRIIb ${ }^{-/-}$mice have been used as a representative lupus model. Interestingly, $\mathrm{FcgRIIb}^{-/-}$mice demonstrated spontaneous endotoxemia without gastrointestinal symptoms at 40 weeks of age. This might be because of gut permeability defects related to the deposition of circulating immune complex in the

J.I.-A. and W.C. contributed equally to this work.
Asada Leelahavanichkul

Immunology Unit, Department of Microbiology

Faculty of Medicine, Chulalongkorn University

Bangkok 10330 (Thailand)

aleelahavanit@gmail.com 
intestine $[5,6]$. Because of the age-dependent development of lupus characteristics, representative models of asymptomatic lupus and symptomatic full-blown lupus can be induced in FcgRIIb ${ }^{-/-}$mice younger and older than 40 weeks, respectively [6]. LPS, a major cell wall component of Gram-negative bacteria, and ( $1 \rightarrow 3)-\beta$-d-glucan (BG), a fungal cell wall component, are dominant in the gastrointestinal tract [7]. Of note, the induction of systemic inflammation models induced by LPS and BG translocated from the gut was reported [8-10] to involve synergistic activity through TLR-4 and dectin-1, receptors for LPS and BG, respectively [11-13]. In addition, severe bacterial sepsis caused by cecal ligation and puncture (CLP) induced glucanemia through sepsis induced gut leakage [14], which enhanced systemic inflammation and sepsis susceptibility in active lupus $\mathrm{FcgRIIb}^{-/-}$mice [6]. Interestingly, the infectious complications of patients with lupus were more prominent with a higher severity, even before the era of immunosuppressive drugs, when compared with the normal population [15]. Likewise, the severity of sepsis in $\mathrm{FcgRIIb}^{-1-}$ mice with symptomatic lupus was higher than that in age-matched WT mice because previous studies reported (i) prominent responses to LPS with or without BG in FcgRIIb ${ }^{-/}$mice $[6,16]$ and (ii) synergistic activity between LPS and BG via TLR-4 and dectin-1, respectively [11-13]. Of note, spleen tyrosine kinase (Syk) is a shared downstream signaling molecule of FcgR, TLR4 , and dectin-1 $[17,18]$, which is activated by stimulators present in active lupus [6], including circulating immune complex, endotoxemia, and glucanemia. Accordingly, Syk is important for FcgR-mediated signal transduction, inflammatory induction, and organismal responses $[17,18]$. In addition, the Syk inhibitor, fostamatinib, previously known as R788, is a US Food and Drug Administration approved drug for the treatment of chronic immune thrombocytopenia [19] and is considered a good candidate for the treatment of other autoimmune diseases. Syk inhibitors attenuate inflammatory processes in several lupus models [20-22] but have never been tested in $\mathrm{FcgRIIb}^{-/-}$mice. Therefore, Syk inhibitors might have significant effects in $\mathrm{FcgRIIb}^{-/-}$mice by rescuing the potent Syk activation caused by FcgR inhibitory signaling defect. Moreover, because there is high prevalence of FcgRIIb dysfunction polymorphisms in the Asian population, further studies to explore Syk inhibitors in $\mathrm{FcgRIIb}^{-/-}$mice as another lupus model might yield promising results for the treatment of lupus patients [4].

Syk inhibitors inhibit FcgR signaling and attenuate TLR-4 activation as demonstrated by the attenuation of LPS-induced sepsis in mice [23]. Despite frequent studies of the therapeutic effects of Syk inhibitors in autoimmune diseases, their effects on sepsis and sepsis preconditioning with lupus characteristics are unclear. The CLP model is a sepsis model with conditions similar to those of lupus patients. The CLP sepsis model and symptomatic lupus model develop gut permeability defect-induced endotoxemia and glucanemia [14]. Hence, a study of the therapeutic effect of Syk inhibitors on sepsis superimposed on lupus is of interest before clinical translation in patients with lupus. LPS and BG are pathogen-associated molecular patterns that mainly activate innate immunity, especially macrophages [11-13], and induce FcgR receptor expression related to adaptive immunity [1-3]; therefore, the simultaneous impact of Syk inhibitors on innate and adaptive immunity warrants further study. Here, we report in vitro and in vivo studies to determine the effect of a Syk inhibitor on sepsis using FcgRIIb ${ }^{-/-}$lupus mice.

\section{Materials and Methods}

\section{Animals}

This study gained approval from the Institutional Animal Care and Use Committee of the Faculty of Medicine, Chulalongkorn University, Bangkok, Thailand, and followed the animal care and use protocol of the National Institutes of Health (NIH), USA. Only female mice were used in experiments. FcgRIIb-deficient mice on a $\mathrm{C} 57 \mathrm{BL} / 6$ background $\left(\mathrm{FcgRIIb}^{-/-}\right)$, a lupus mouse model, were provided by Dr. Silvia Bolland (NIAID, NIH, Maryland, USA) and female wild-type (WT) mice were purchased from the Nomura Siam International (Pathumwan, Bangkok, Thailand). FcgRIIb ${ }^{-1-}$ mice develop anti-dsDNA antibodies as early as 16-24 weeks and have increased serum creatinine ( $\mathrm{Scr}$ ) levels at 40 weeks of age, indicating lupus nephritis [6, $24,25]$. Therefore, FcgRIIb ${ }^{-l-}$ mice at 24 and 40 weeks of age were used as representative models of asymptomatic and symptomatic lupus, respectively.

\section{Induction of the CLP Sepsis Model and Syk Inhibitor} Administration

CLP was induced following a previous publication [6] with some modifications to induce polymicrobial sepsis in asymptomatic and symptomatic lupus mice. In brief, cecal puncture with a 21 -gauge needle was performed under isoflurane anesthesia. Tramadol, $20 \mathrm{mg} / \mathrm{kg}$ diluted in $0.5 \mathrm{~mL}$ normal saline, and antibiotic (imipenem/cilastatin), at $14 \mathrm{mg} / \mathrm{kg}$ in $0.5 \mathrm{~mL}$ normal saline, were administered subcutaneously after surgery and at $6 \mathrm{~h}$ after CLP. Mice were sacrificed at $24 \mathrm{~h}$ after CLP under isoflurane anesthesia for tissue sample collection. The collected serum was kept at $-80^{\circ} \mathrm{C}$ until analysis. A Syk inhibitor (R788 disodium; Selleckchem, Houston, TX, USA) in $0.1 \mathrm{M}$ citrate buffer ( $\mathrm{pH} \mathrm{6.8)}$ ) at $25 \mathrm{mg} / \mathrm{kg}$ / dose was orally administered in 2 separate groups of experiments including (i) daily oral administration for 14 days prior to CLP and at $6 \mathrm{~h}$ after CLP surgery and (ii) daily oral administration for 3 days prior to CLP and at $6 \mathrm{~h}$ after CLP surgery. Blood collection through tail vein was performed 2 days prior to CLP and at sacrifice for pre- 
Table 1. List of primers used in this study

\begin{tabular}{lll}
\hline Primers & Forward & Reverse \\
\hline Arginase-1 (Arg-1) & 5'-CTTGGCTTGCTTCGGAACTC-3' & 5'-GGAGAAGGCGTTTGCTTAGTTC-3' $^{\prime}$ \\
Transforming growth factor- $\beta$ (TGF- $\beta$ ) & 5'-CAGAGCTGCGCTTGCAGAG-3' & $5^{\prime}$-GTCAGCAGCCGGTTACCAAG-3' \\
Resistin-like molecule- $\alpha$ (FIZZ-1) & $5^{\prime}$-GCCAGGTCCTGGAACCTTTC-3' & $5^{\prime}$-GGAGCAGGGAGATGCAGATGAG-3' \\
Interleukin-10 (IL-10) & $5^{\prime}$-GCTCTTACTGACTGGCATGAG-3' & $5^{\prime}$-CGCAGCTCTAGGAGCATGTG-3' \\
Inducible nitric oxide synthase (iNOS) & $5^{\prime}$-ACCCACATCTGGCAGAATGAG-3' & $5^{\prime}$-AGCCATGACCTTTCGCATTAG-3' \\
Tumor necrosis factor- $\alpha$ & $5^{\prime}$-CCTCACACTCAGATCATCTTCTC-3' & $5^{\prime}$-AGATCCATGCCGTTGGCCAG-3' \\
Interleukin-1 $\beta$ & $5^{\prime}$-GAAATGCCACCTTTTGACAGTG-3' & $5^{\prime}$-TGGATGCTCTCATCAGGACAG-3' \\
Spleen tyrosine kinase (Syk) & $5^{\prime}$-CTACTACAAGGCCCAGACCC-3' & $5^{\prime}$-TGATGCATTCGGGGGCGTAC-3' \\
$\beta$-Actin & $5^{\prime}$-CGGTTCCGATGCCCTGAGGCTCTT-3' & $5^{\prime}$-CGTCACACTTCATGATGGAATTGA-3' \\
\hline
\end{tabular}

and post-CLP parameters, respectively. Then, blood was collected through tail vein or cardiac puncture to explore lupus characteristics including Scr (QuantiChrom Creatinine Assay, DICT-500; BioAssay, Hayward, CA, USA), serum anti-dsDNA by a protocol using coated calf DNA (Invitrogen, Carlsbad, CA, USA) [26], and serum cytokines by ELISA (PeproTech, Oldwick, NJ, USA). Symptomatic lupus was defined as increased serum anti-dsDNA antibodies and high Scr compared with age-matched control WT mice. In addition, endotoxin (LPS) was measured as a parameter for sepsis severity using the Limulus Amebocyte lysate test (Associates of Cape Cod, East Falmouth, MA, USA). Values of LPS $<0.01$ $\mathrm{EU} / \mathrm{mL}$ were recorded as 0 .

\section{Gut Permeability Determination}

Fluorescein isothiocyanate-dextran (FITC-dextran), a gut nonabsorbable molecule, was orally administered to determine gut permeability, as previously published [14]. Briefly, FITC-dextran (molecular weight $4.4 \mathrm{kDa}, \mathrm{FD} 4$; Sigma, St. Louis, MO, USA) at 0.5 $\mathrm{mL}(25 \mathrm{mg} / \mathrm{mL})$ diluted in sterile PBS was administered, and serum FITC-dextran was measured by fluorospectrometry (microplate reader; Thermo Scientific, Wilmington, DE, USA) after $3 \mathrm{~h}$. Spontaneous increases in $(1 \rightarrow 3)$ - $\beta$-d-glucan $(B G)$ in serum, without systemic fungal infection, measured by Fungitell assay (Associates of Cape Cod), were used as an indicator of gut leakage. Values of $\mathrm{BG}<7.8 \mathrm{pg} / \mathrm{mL}$ were recorded as 0 .

\section{Histology Analysis}

Semiquantitative evaluation of renal histology on paraffin-embedded slides was performed after 10\% neutral buffered formalin fixation, followed by hematoxylin and eosin (H\&E) staining [27, 28]. In brief, sepsis-induced renal injury (defined as tubular epithelial swelling, loss of brush border, vacuolar degeneration, necrotic tubules, cast formation, and desquamation) was performed at $\times 200$ magnification in 10 randomly selected fields for each animal using the following scoring method: 0 , area of damage $<5 \% ; 1$, area of damage $5-10 \% ; 2$, area of damage $10-25 \%$; 3 , area of damage $25-50 \%$; and 4 , area of damage $>50 \%$.

\section{Western Blot Analysis}

Isolated internal organs were maintained at $-80^{\circ} \mathrm{C}$ until use for Western blot analysis, as previously described [29]. In brief, $20 \mu \mathrm{g}$ of homogenized tissue, as measured by bicinchoninic acid assay (Thermo Fisher Scientific), was used for SDS-PAGE following the standard procedures before incubation with specific primary antibodies against Syk (Cell signaling, Beverly, MA, USA) or glyceraldehyde 3-phosphate dehydrogenase (Cell signaling) overnight at $4^{\circ} \mathrm{C}$. Then, a secondary antibody linked with horseradish peroxidase enzyme was used and visualized by ImageQuant ${ }^{\mathrm{TM}}$ LAS 500 (GE-Healthcare, Little Chalfont, Buckinghamshire, UK).

\section{Bone-Marrow-Derived Macrophages and Supernatant}

Cytokines

Macrophages were derived from bone marrow following a published protocol $[29,30]$. In parallel, heat-killed Candida albicans, the representative fungus, was prepared by heating at $65^{\circ} \mathrm{C}$ for 15 $\mathrm{min}$, followed by sonication with a high intensity ultrasonic processor (VC/VCX 130, 500,750) at 25\% amplitude until a clear solution was obtained. Macrophages $\left(1 \times 10^{5}\right.$ cells/well $)$ were incubated with the heat-killed C. albicans preparation (HK-fungi) with or without LPS (Escherichia coli 026:B6; Sigma-Aldrich) at $100 \mathrm{ng}$ / $\mathrm{mL}$ or supplemented with DMEM alone (control) for $6 \mathrm{~h}$ before the measurement of supernatant cytokines (PeproTech). In addition, to determine different influences of the Syk inhibitor against the activation of FcgRIIb ${ }^{-/}$and WT macrophages by heat-killed C. albicans with LPS, macrophages were preconditioned with active metabolites of the Syk inhibitor (R406) (Selleckchem) at $10 \mu \mathrm{g} /$ $\mathrm{mL}$ or DMEM alone (control) for $1 \mathrm{~h}$ prior to a 6 -h incubation of the fungal preparation with LPS and before supernatant cytokine measurement.

\section{Real-Time PCR for Macrophage Polarization and Syk}

Expression

Macrophage polarization is associated with pro- or anti-inflammatory effects, termed M1 or M2 polarization, respectively [31], and the proinflammatory properties of FcgRIIb ${ }^{-/}$macrophages are prominent [1]. Therefore, the polarization of macrophages from WT and $\mathrm{FcgRIIb}^{-/-}$after induction might be different. Accordingly, macrophages at $2 \times 10^{6}$ cells per well were incubated with whole glucan particle (WGP), representative of BG, purified from Saccharomyces cerevisiae $\left(\mathrm{WGP}^{\circledR}\right.$ Dispersible; Biothera), at $100 \mu \mathrm{g} / \mathrm{mL}$ with or without LPS (100 ng/mL) for $6 \mathrm{~h}$. Then, total RNA was prepared using an RNeasy Mini Kit (Qiagen, Hilden, Germany), and the reverse transcription of $0.3 \mu \mathrm{g}$ total RNA was performed using a high capacity reverse transcription assay (Applied Biosystems, Warrington, UK) according to the manufacturer's instructions. Real-time PCR was performed using an Applied Biosystems 7500 Real-Time PCR System (Applied Bio- 


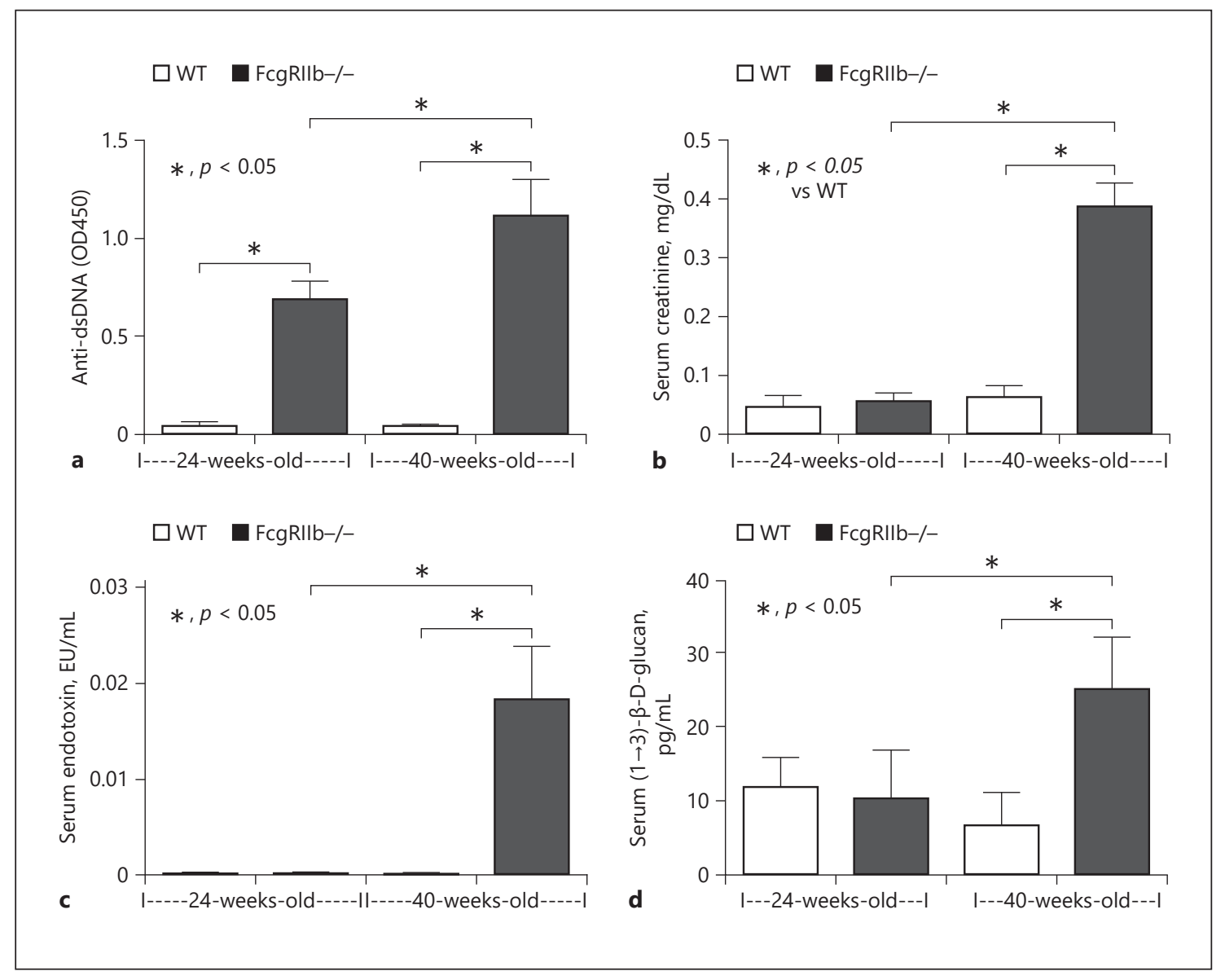

Fig. 1. Lupus characteristics of FcgRIIb ${ }^{-1-}$ mice. Characteristics of FcgRIIb ${ }^{-1-}$ mice at 24 (early onset of lupus) and 40 weeks of age (full-blown lupus) or age-matched wild-type (WT) mice as determined by serum antidsDNA (a), renal injury (serum creatinine) (b), endotoxemia $(\mathbf{c})$, and serum $(1 \rightarrow 3)$ - $\beta$-D-glucan $(\mathbf{d})(n=5-7 /$ group).

systems) with SYBR ${ }^{\circledR}$ Green PCR Master Mix (Applied Biosystems). The results were indicated in terms of relative quantitation using the comparative threshold (delta-delta $C_{t}$ ) method. The expression of target genes in the sample, normalized to $\beta$-actin (an endogenous housekeeping gene), was demonstrated. A list of primers for PCR is shown in Table 1.

\section{RNA Sequencing}

RNA sequencing was performed to determine the influence of a Syk inhibitor on FcgRIIb ${ }^{-1-}$ and WT macrophages after activation by WGP $(500 \mu \mathrm{g} / \mathrm{mL})$ plus LPS $(100 \mathrm{ng} / \mathrm{mL})$. FcgRIIb ${ }^{-1}$ and WT macrophages were treated with a combination of WGP and LPS, with and without the active form of the Syk inhibitor, R406 (Selleckchem), at $10 \mu \mathrm{g} / \mathrm{mL}$ for $6 \mathrm{~h}$. Then, the cells were collected for RNA extraction using an RNeasy mini kit (Qiagen). RNA sequencing was performed by the BGI Company. Differential gene expression was determined using $\mathrm{R}$ package. Biological process and pathway analysis were performed using $\mathrm{GO}$ analysis and gene ontology pathway analysis, respectively.

\section{Statistical Analysis}

Statistical differences among groups were examined using the unpaired Student's $t$ test or one-way ANOVA with Tukey's comparison test for the analysis of experiments with 2 groups or more than 2 groups, respectively, and are presented as the mean \pm SE. Statistical comparisons of data before and after treatment were conducted by paired Student's $t$ test. SPSS 11.5 software (SPSS, Chicago, IL, USA) was used for all statistical analyses.

Fig. 2. Expression of activated genes in activated macrophages. Gene expression of macrophage after $6 \mathrm{~h}$ activation by whole glucan particle (WGP), representative of $(1 \rightarrow 3)-\beta$-D-glucan, with or without LPS in FcgRIIb ${ }^{-1}$ and wild-type (WT) macrophages, as determined by proinflammatory genes (TNF- $\alpha$ and $i N O S)(\mathbf{a}, \mathbf{b})$, anti-inflammatory genes (IL-10, Fizz-1, Arginase-1, and TGF- $\beta$ ) $(\mathbf{c}-\mathbf{f})$, and spleen tyrosine kinase $(S y k)(\mathbf{g})$. Independent triplicate experiments were performed.

(For figure see next page.) 

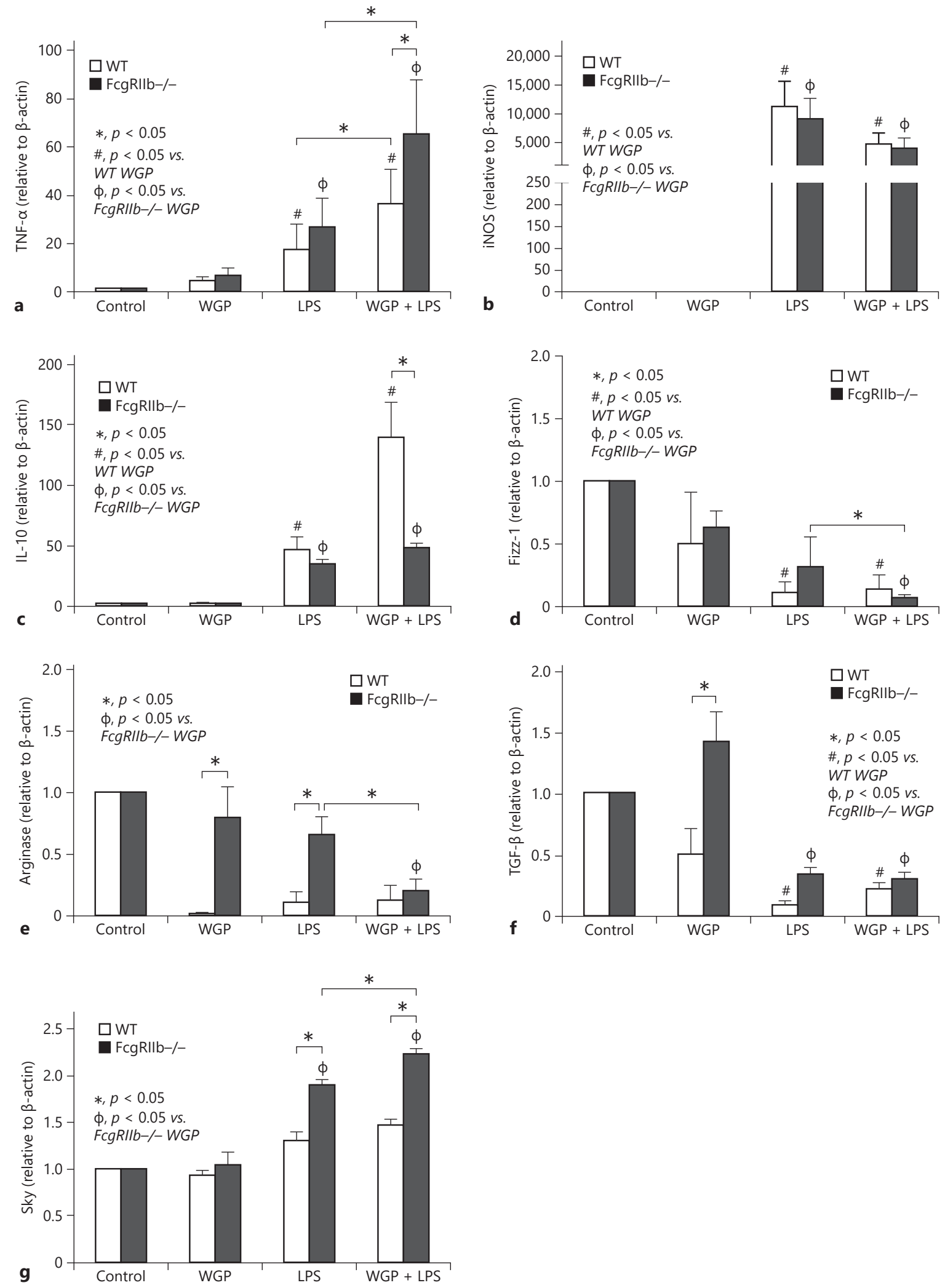


\section{Results}

Asymptomatic and Symptomatic Lupus

Characteristics in 24- and 40-Week-Old FcgRIIb ${ }^{-/-}$

Mice

Lupus characteristics including anti-dsDNA antibodies and Scr were evaluated. Anti-dsDNA antibodies were elevated as early as 24 weeks of age in $\mathrm{FcgRIIb}^{-/-}$mice, whereas Scr was increased at 40 weeks of age, indicating renal injury (Fig. 1a, b). Spontaneous gut permeability defects as determined by the elevation of endotoxin (LPS) and BG in serum were demonstrated in 40-week-old FcgRIIb $^{-/-}$mice (Fig. 1c, d). Levels of anti-dsDNA antibody, but not of other parameters, were increased in 24-week-old FcgRIIb ${ }^{-/}$mice (Fig. 1). These characteristics confirmed symptomatic and asymptomatic lupus were induced in $\mathrm{FcgRIIb}^{-1-}$ mice, as previously published [6].

\section{Prominent Responses against Bacterial and Fungal}

Molecules in FcgRIIb ${ }^{-/-}$Macrophages Compared with WT Macrophages

Because LPS and BG in the serum of symptomatic lupus mice might activate macrophages, gene expression related to macrophage polarization was investigated. LPS, a potent proinflammatory inducer, enhanced the expression of the proinflammatory genes, $T N F-\alpha$ and $i N O S$, and increased the expression of the anti-inflammatory gene, $I L-10$, to similar levels in WT and FcgRIIb ${ }^{-/-}$macrophages (Fig. 2a-c). The addition of WGP, a representative BG, enhanced LPS-induced TNF- $\alpha$ expression, but not $i N O S$, and decreased $I L-10$ expression in $\mathrm{FcgRIIb}^{-/-}$macrophages (Fig. $2 \mathrm{a}-\mathrm{c}$ ), suggesting proinflammatory synergy between BG and LPS. In parallel, activation with LPS, with and without WGP, had a minor effect on the expressions of other anti-inflammatory genes including Fizz-1, Arginase-1, and TGF- $\beta$, which were lower than in the control group (Fig. $2 \mathrm{c}-\mathrm{f}$ ), except for activation by WGP alone in FcgRIIb ${ }^{-/}$cells (Fig. 2f). These data suggest that WGP plus LPS enhanced the proinflammatory characteristics of FcgRIIb ${ }^{-1-}$ macrophages compared with WT macrophages. Furthermore, the expression of $S y k$, the shared downstream signaling factor of WGP and LPS [32], was higher in FcgRIIb ${ }^{-/-}$macrophages after activation by LPS alone or LPS with WGP (LPS + WGP) compared with WT macrophages (Fig. 2g). Syk expression in FcgRIIb ${ }^{-1-}$, but not WT, macrophages after activation with LPS + WGP was higher than when activated with LPS alone (Fig. 2g).

To explore further influence of combined bacterial and fungal molecules on macrophages, levels of cytokines including TNF- $\alpha$, IL- 6 , and IL-10 were measured in the supernatant after the cells were activated by LPS with or without heat-killed C. albicans (HK-fungi). All groups showed elevated supernatant cytokines; however, activation by LPS alone was more potent than HK-fungi alone in both strains of macrophages (Fig. 3a-c). Stimulation by HK-fungi (alone) similarly elevated supernatant levels of cytokines from both strains of macrophages, whereas LPS (alone) induced higher levels of cytokines in $\mathrm{FcgRIIb}^{-/-}$macrophages compared with WT macrophages (Fig. $3 \mathrm{a}-\mathrm{c}$ ). Compared with stimulation by LPS alone, LPS plus HK-fungi (LPS + HK-fungi) enhanced TNF- $\alpha$ and IL-6 levels, but not IL-10, in FcgRIIb ${ }^{-1-}$ macrophages and increased IL-10, but not other cytokines, in WT macrophages (Fig. 3a-c). This suggests that $\mathrm{FcgRIIb}^{-/-}$macrophages were more proinflammatory compared with WT macrophages. In addition, after activation by LPS + HK-fungi, the Syk inhibitor attenuated all supernatant cytokines in $\mathrm{FcgRIIb}^{-/-}$macrophages but only IL-6 in WT macrophages (Fig. 3d-f).

\section{Prominent Effect of the Syk Inhibitor on FcgRIIb ${ }^{-/-}$}

Macrophages Compared with WT Macrophages: RNA

Sequencing Analysis

We observed a prominent anti-inflammatory effect of the Syk inhibitor on FcgRIIb ${ }^{-1-}$ macrophages compared with WT macrophages. Therefore, RNA sequencing was performed to investigate the potential pathways involved. The numbers of genes expressed in FcgRIIb ${ }^{-1-}$ macrophages after activation by WGP plus LPS (WGP + LPS) with or without a Syk inhibitor or in the negative control (culture media without pathogenic molecules) were similar (Fig. 4a). However, the Syk inhibitor suppressed most of the expressed genes in WGP + LPS activated FcgRIIb ${ }^{-1-}$ macrophages (Fig. 4b). In addition, the comparison of differentially expressed genes in $\mathrm{FcgRIIb}^{-/-}$macrophages with negative control FcgRIIb $^{-/-}$macrophages after stimulation with WGP + LPS demonstrated the upregulation of proinflammatory genes (TNF- $\alpha, N F-\kappa B$, and MAPK) and the downregulation of genes in metabolic pathways (Fig. 4c). In groups treated with the Syk inhibitor, differentially expressed genes in most pathways including the signaling pathways of TNF- $\alpha$, Toll-like receptor, and NF- $\kappa \mathrm{B}$ were downregulated (Fig. 4d).

Interestingly, the direction of gene expression (up- or downregulation) in WGP + LPS activated FcgRIIb ${ }^{-/}$ macrophages, compared with the negative control, was similar to genes associated with high mortality rate in patients with sepsis [33]. Most upregulated genes in pa- 


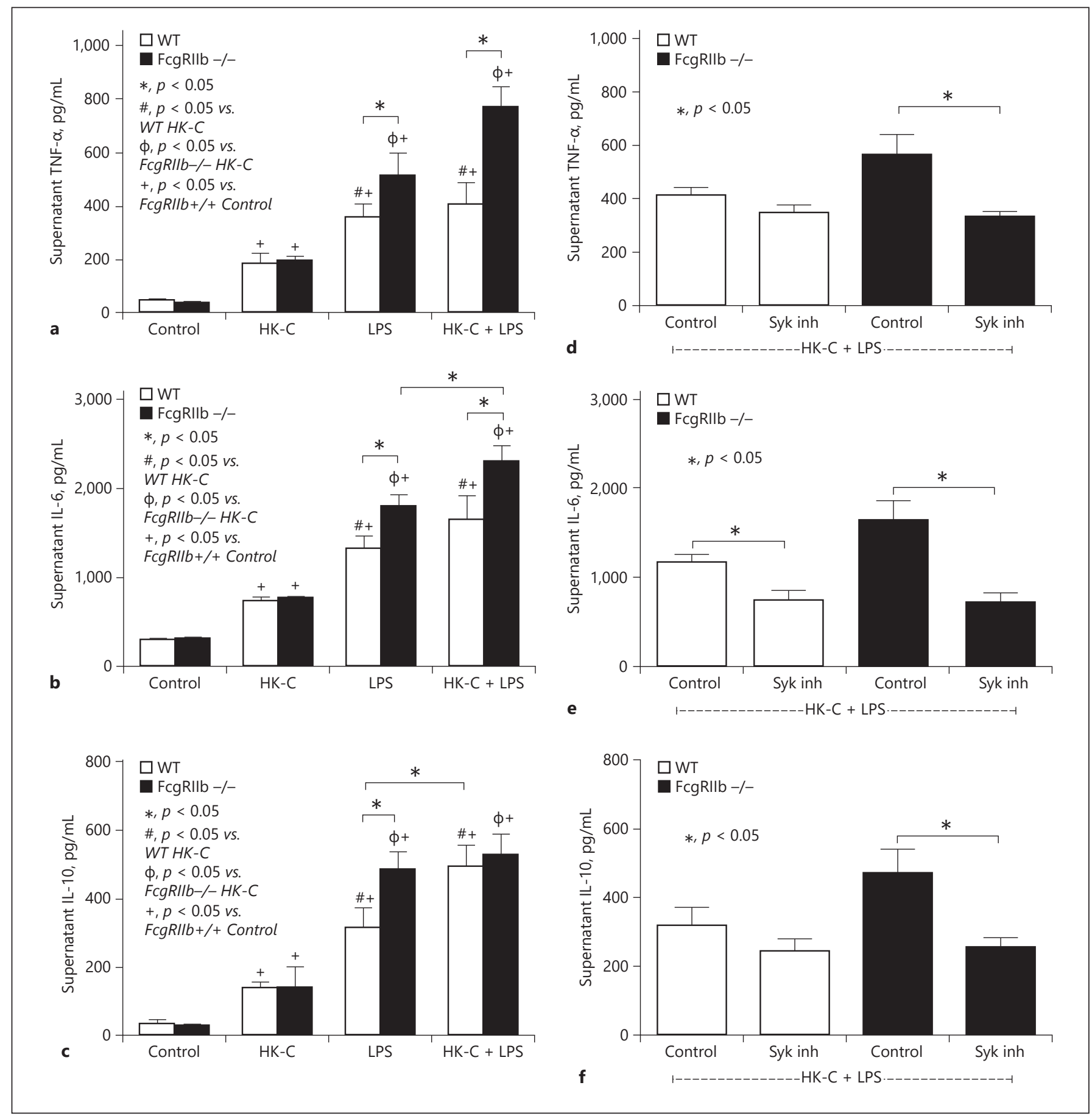

Fig. 3. Supernatant cytokine levels of activated macrophages. Supernatant cytokines secreted by macrophages from FcgRIIb ${ }^{-1}$ and wild-type (WT) mice after $6 \mathrm{~h}$ incubation with heat-killed Candida albicans (HK-C) with or without LPS (a-c). The effect of a Syk inhibitor against supernatant cytokine secretion by HK-C with LPS in $\mathrm{FcgRIIb}^{-1-}$ and WT mice (d-f). Independent triplicate experiments were performed. 

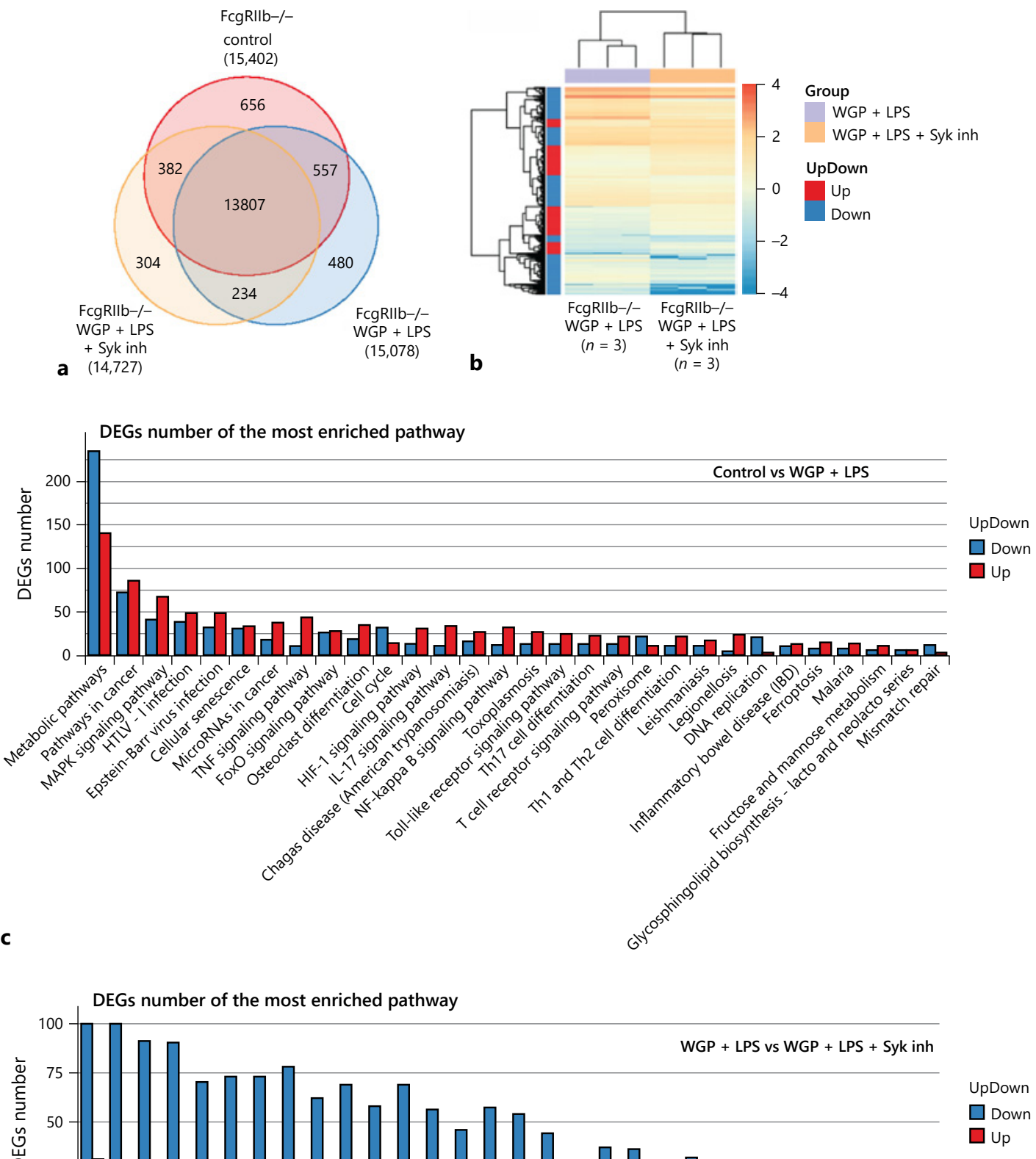

d

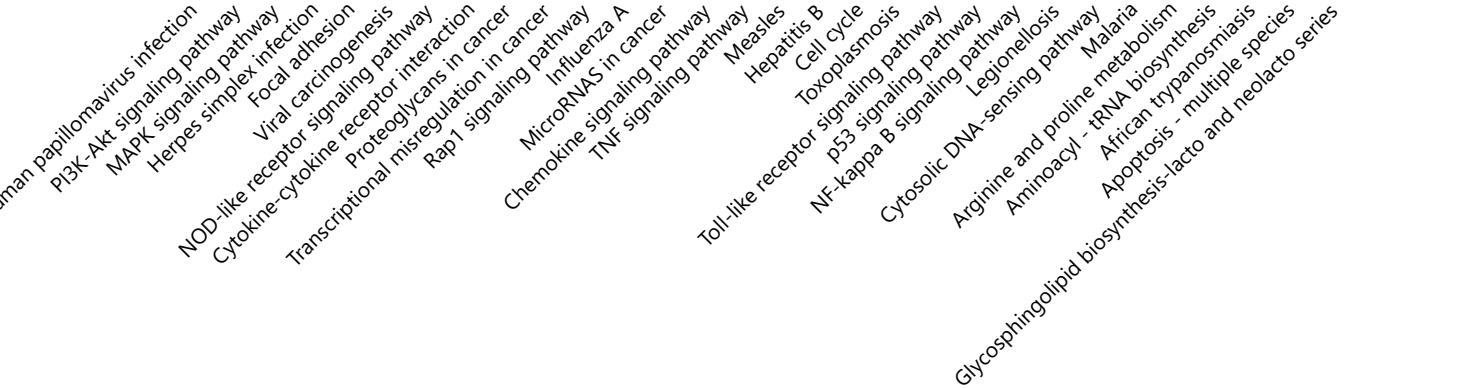

4

(For legend see next page.) 
tients with severe sepsis, except $P L K 1$ and $C D-163$, were also upregulated in WGP + LPS activated FcgRIIb ${ }^{-1-}$ macrophages (Fig. 5; control vs. WGP + LPS). Likewise, most downregulated genes in patients with severe sepsis, except AIM2, GSTM1, and VNN3, were downregulated in WGP + LPS activated FcgRIIb ${ }^{-1}$ macrophages (Fig. 5; control vs. WGP + LPS). These data indicated the similarity between genes expressed in patients with severe sepsis and those expressed in WGP + LPS activated FcgRIIb $^{-1-}$ macrophages. Of note, the Syk inhibitor reversed the direction of the expressed genes in WGP + LPS activated FcgRIIb ${ }^{-1-}$ macrophages (Fig. 5; WGP + LPS vs. WGP + LPS + Syk inhibitor), indicating Syk inhibitors might be a potential candidate for sepsis treatment in lupus.

\section{High Levels of Syk in FcgRIIb ${ }^{-1-}$ Mice and Sepsis Attenuation by Syk Inhibition}

Because Syk is a shared downstream signaling factor of FcgR, TLR-4, and dectin-1 $[34,35]$ and was activated by anti-dsDNA antibodies, LPS, and BG in symptomatic FcgRIIb $^{-/-}$mice (Fig. 1), we investigated the levels of Syk in FcgRIIb ${ }^{-/-}$and WT mice. Syk levels were higher in the spleen than in other organs in FcgRIIb ${ }^{-/-}$mice at 24 and 40 weeks of age, and in WT mice at 40 weeks, but not 24 weeks, of age (Fig. 6a). Syk levels in the spleens of 40week-old WT mice were similar to those in 24-weekold FcgRIIb ${ }^{-1-}$ mice, and Syk levels in 40-week-old FcgRIIb $^{-1}$ mice were highest among all groups (Fig. 6a). In addition, Syk levels in spleens were enhanced by CLP sepsis in both mouse strains, but levels were highest in $\mathrm{FcgRIIb}^{-1-}$ mice with sepsis (Fig. 6b). Because Syk levels were increased in the spleens of CLP sepsis mice, we investigated the effect of the Syk inhibitor in vivo.

The mortality rate of CLP sepsis in 40-week-old $\mathrm{FcgRIIb}^{-1-}$ mice was higher than that in age-matched WT

Fig. 4. RNA sequencing analysis of activated macrophages. Venn diagram of the RNA sequencing analysis demonstrating gene expression of $\mathrm{FcgRIIb}^{-/-}$macrophages after $6 \mathrm{~h}$ activation with whole glucan particle (WGP) and LPS (WGP + LPS) with or without Syk inhibitor (Syk inh) or control culture media (Control) (a). A heat map of differentially expressed genes in activated FcgRIIb ${ }^{-1-}$ macrophages by WGP + LPS with or without a Syk inhibitor (b). Comparison of differentially expressed genes (DEGs) from the most enriched pathways between activated $\mathrm{FcgRIIb}^{-1-}$ macrophages and control culture media (Control vs. WGP + LPS) (c) and between activated $\mathrm{FcgRIIb}^{-/-}$macrophages with or without a Syk inhibitor (WGP + LPS vs. WGP + LPS + Syk inhibitor) (d) $(n=3 /$ group).

Syk Activation in Lupus Mouse Models of FcgRIIb $^{-1-}$ with Sepsis sepsis mice, but a similar mortality rate was observed for 24-week-old mice of either strains (Fig. 7a, b). Furthermore, the mortality rate of sepsis in $\mathrm{FcgRIIb}^{-/-}$mice aged 40 weeks was higher than that in 24-week-old mice (Fig. 7c). Organ injury determined by Scr, renal histology, liver enzyme (ALT) (Figs. 7d-i, 8), gut leakage (FITCdextran, serum LPS, and serum BG) (Fig. 9), and inflammatory cytokines (Fig. 10) at $24 \mathrm{~h}$ post-CLP was more severe in 40-week-old FcgRIIb ${ }^{-1-}$ mice than in 24-weekold FcgRIIb ${ }^{-1-}$ mice or WT mice. Levels of anti-dsDNA antibodies were higher in 40-week-old FcgRIIb ${ }^{-1-}$ mice than in 24-week-old FcgRIIb ${ }^{-1-}$ mice, and sepsis did not alter anti-dsDNA antibody levels (Fig. 7j-1). In addition, there was preconditioning damage in 40-week-old $\mathrm{FcgRIIb}^{-/-}$mice (pre-CLP), as indicated by the higher baseline levels of Scr (Fig. 7f), gut leakage (Fig. 9c, f, i), and inflammatory cytokines (Fig. 10c, f, i), but not ALT or anti-dsDNA antibodies (Fig. 7i, 1), compared with 24-week-old FcgRIIb ${ }^{-/}$mice, which might explain the higher sepsis mortality rate in 40 -week-old FcgRIIb ${ }^{-/}$ mice compared with 24-week-old $\mathrm{FcgRIIb}^{-1-}$ mice (Fig. 7c). In parallel, there was no preconditioning injury in 24-week-old FcgRIIb ${ }^{-/-}$mice compared with agematched WT mice by these pre-CLP parameters (Figs. 7-10), except for anti-dsDNA antibodies (Fig. 7j), resulting in a similar mortality rate of CLP sepsis between 24-week-old FcgRIIb ${ }^{-1-}$ mice and age-matched WT mice (Fig. 7a).

Compared with the PBS control group, after 14-day administration of a Syk inhibitor prior to CLP surgery, the severity of sepsis was lower in 40 -week-old FcgRIIb ${ }^{-1-}$ mice, but not 24-week-old FcgRIIb ${ }^{-1-}$ mice and WT mice, as determined by mortality rate and several post-CLP parameters including Scr, renal histology, liver damage (ALT) (Figs. 7, 8), and inflammatory cytokines (Fig. 10). Furthermore, the Syk inhibitor did not decrease the severity of sepsis-induced gut leakage, as indicated by FITCdextran and serum BG (Fig. 9b, h), but did attenuate serum LPS levels (Fig. 9e), which might explain the attenuation of sepsis severity. However, 14-day treatment with the Syk inhibitor reduced baseline proinflammation, as indicated by reduced levels of pre-CLP serum cytokines (Fig. 10b, e, h) despite no effect on Scr, anti-dsDNA antibodies (Fig. 7e, k), or gut leakage (Fig. 9b, e, f). These data indicate the importance of preconditioning injury upon sepsis severity $[28,36]$. Indeed, the 3 -day administration of a Syk inhibitor prior to CLP did not decrease pre-CLP serum cytokine levels or sepsis severity in lupus mice of both ages (Fig. 11). 
Fig. 5. Comparison of gene expression between activated macrophages and patients with severe sepsis. A heat map comparison of the up- and downregulated genes in macrophages associated with genes expressed in patients with high mortality rate sepsis. Left column: fold change in gene expression after activation of FcgRIIb ${ }^{-1-}$ macrophages by whole glucan particle (WGP), a representative of $(1 \rightarrow 3)-\beta$-Dglucan, and LPS (WGP + LPS) versus Control. Right column: fold change in gene expression of FcgRIIb ${ }^{-/}$macrophages activated by WGP + LPS with Syk inhibition (WGP + LPS + Syk inh) versus no Syk inhibition (WGP + LPS).

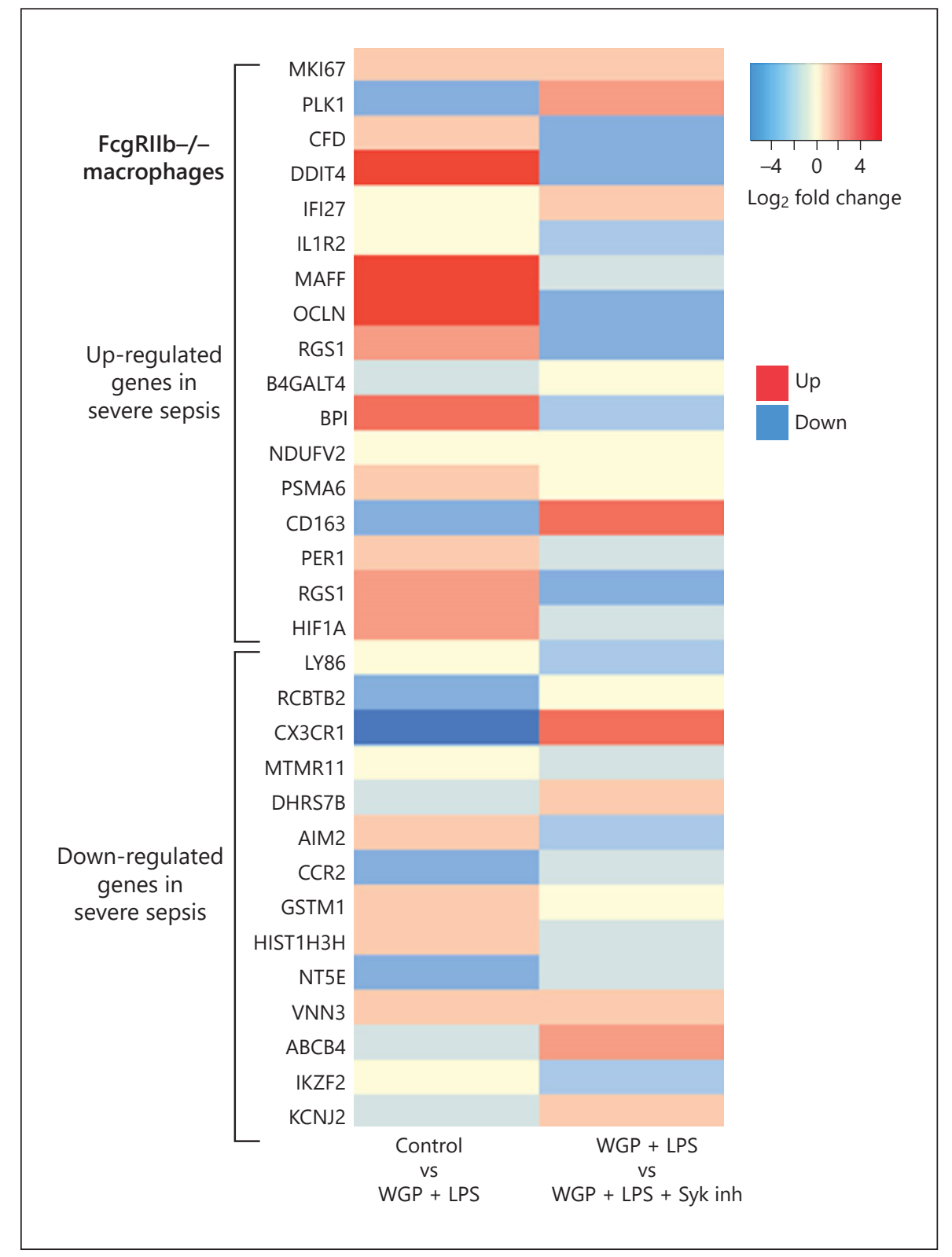

\section{Discussion}

Serum inflammatory cytokines and Syk signaling in $\mathrm{FcgRIIb}^{-/-}$mice at baseline before CLP operation were higher than in WT mice. This might be related to Sykmediated preconditioning injury caused by immune complex, endotoxemia, and glucanemia in active lupus. Marked Syk activation in FcgRIIb ${ }^{-/-}$mice with sepsis compared with WT mice might explain the therapeutic effect of Syk inhibitor in lupus with sepsis.
More Severe Sepsis in Full-Blown Lupus in FcgRIIb ${ }^{-1-}$ Mice Compared with WT Mice: Impact of Preconditioning Inflammation through Gut Permeability Defects

Spontaneously developed lupus characteristics including anti-dsDNA antibodies and renal injuries (Scr and renal pathology) caused by hyper-immune responsiveness related to a defect in negative signaling [1] were demonstrated in 40-week-old FcgRIIb ${ }^{-/-}$mice, a full-blown lupus model. In parallel, it was shown that prominent intestinal deposition of immune complex with gut perme-
Issara-Amphorn/Chancharoenthana/ Visitchanakun/Leelahavanichkul 


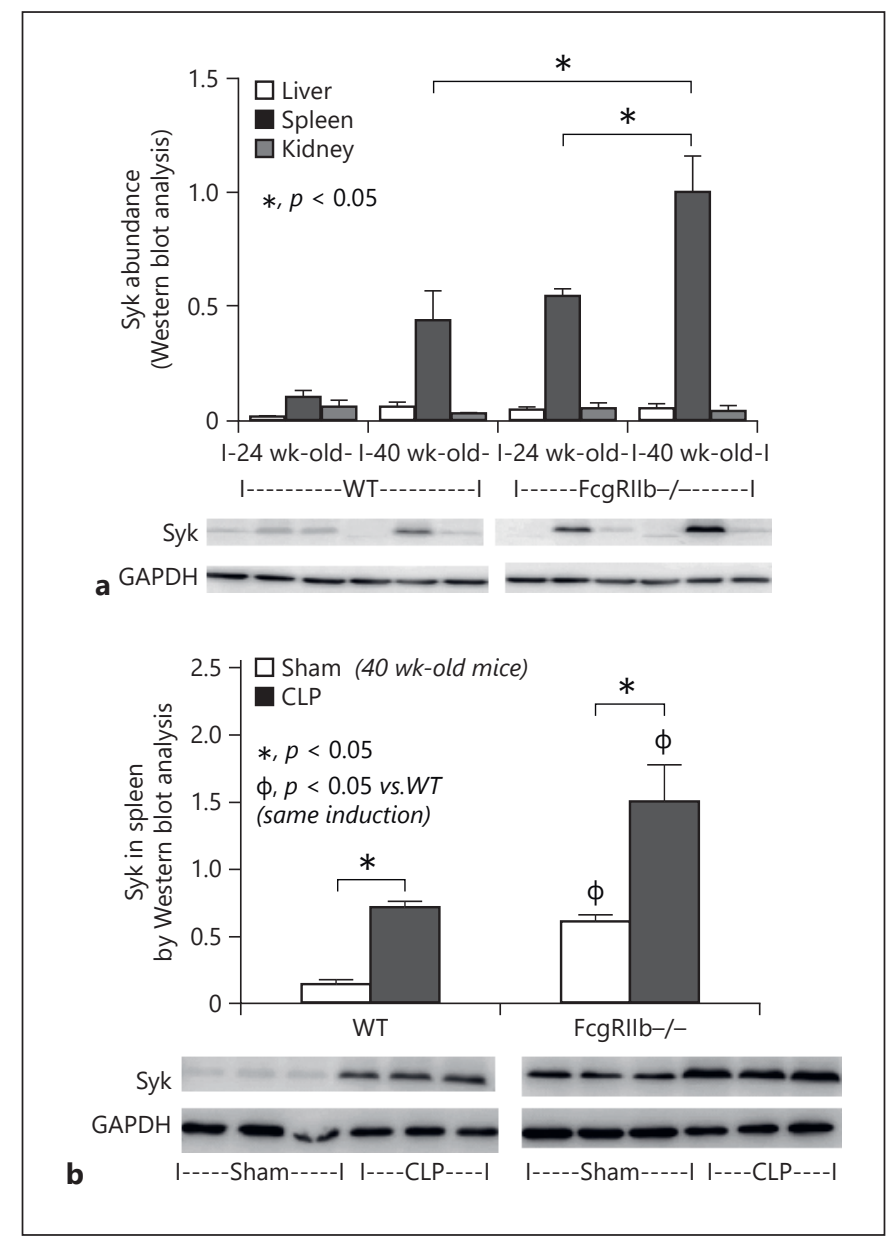

Fig. 6. Syk abundance in mouse organs. Syk levels in organs from wild-type (WT) and FcgRIIb ${ }^{-/-}$mice aged 24 and 40 weeks. a Western blot analysis without cecal ligation and puncture (CLP) ( $n=5$ /group). b Syk levels in spleens of 40 -week-old WT and FcgRIIb $^{-/-}$mice $24 \mathrm{~h}$ after CLP or sham surgery (Sham) $(n=5 /$ group).

ability defects induced endotoxemia/glucanemia in 40-week-old FcgRIIb ${ }^{-/-}$mice, leading to more severe sepsis than in WT mice [6]. Although endotoxemia in the CLP model cannot be used as an indicator of gut leakage because of sepsis-induced Gram-negative bacteremia, glucanemia without fungemia did indicate sepsis-induced leaky gut [14]. Nevertheless, LPS and BG are pathogenic molecules foreign to the host, which synergistically activate innate immune responses in the host through TLR-4 and dectin-1, respectively [32], resulting in systemic inflammatory responses $[6,8,9,14,37]$. Indeed, gut leakage and levels of systemic cytokines before sepsis induction and sepsis severity in 40-week-old FcgRIIb ${ }^{-1-}$

Syk Activation in Lupus Mouse Models of FcgRIIb $^{-1-}$ with Sepsis mice (full-blown lupus) were higher than those in 24-week-old FcgRIIb ${ }^{-1-}$ mice (asymptomatic lupus). Accordingly, enhanced sepsis severity after preconditioning inflammation in 40-week-old FcgRIIb ${ }^{-/-}$mice supports the impact of chronic inflammation at baseline (before sepsis induction) on sepsis severity [28, 36, 38-40], similar to other 2-hit sepsis models [41-43]. Therefore, the attenuation of baseline systemic inflammation in fullblown lupus mice, before CLP induction, might be a good strategy to reduce sepsis severity.

\section{High Syk Signaling in FcgRIIb ${ }^{-1-}$ Lupus Mice and}

Marked Anti-Inflammatory Effects of a Syk Inhibitor

in Lupus: Potential for Clinical Translation

Syk is a shared downstream signaling factor of $\mathrm{FcgR}$, TLR-4, and dectin-1 [34]. Interestingly, the stimulatory molecules of these receptors, including anti-dsDNA antibodies, LPS, and BG, were presented in the serum of 40-week-old FcgRIIb ${ }^{-1-}$ mice, but not WT mice, because of lupus-induced gut permeability defects [6]. Indeed, levels of Syk in the spleens of fully developed lupus FcgRIIb $^{-/-}$mice at 40 weeks of age were higher than in age-matched WT mice. In addition, activation of FcgRIIb $^{-/}$macrophages by LPS alone, or LPS + BG, was more potent than the activation of WT macrophages, as indicated by higher cytokine production and enhanced Syk expression supporting the hyper-responsiveness of FcgRIIb $^{-1-}$ macrophages [1]. In WT macrophages, activation by LPS + BG increased the expression of TNF- $\alpha$, a proinflammatory cytokine, and increased the expression of $I L-10$ and levels of supernatant IL-10, which are antiinflammatory biomarkers, compared with activation by LPS alone. There appeared to be a balance between proand anti-inflammatory responses in WT macrophages after LPS + BG activation.

However, LPS + BG activation of FcgRIIb ${ }^{-1-}$ macrophages increased the expressions of TNF- $\alpha$ and $S y k$, but reduced $I L-10$ expression, together with increased TNF- $\alpha$ and IL-6, but not IL-10 levels, in the supernatant, supporting the activation of LPS + BG through Syk signaling and the synergistic proinflammatory effect of LPS + BG [32]. The activation of FcgRIIb ${ }^{-/-}$macrophages by LPS + BG shifted toward a proinflammatory response, which might be related to the loss of inhibitory signaling through FcgRIIb. Furthermore, the greater anti-inflammatory effect of the Syk inhibitor in FcgRIIb ${ }^{-/-}$macrophages compared with WT macrophages might indicate the greater impact of Syk signaling in lupus.

Although it was previously demonstrated that Syk inhibitor attenuated sepsis in LPS model (a model induced 


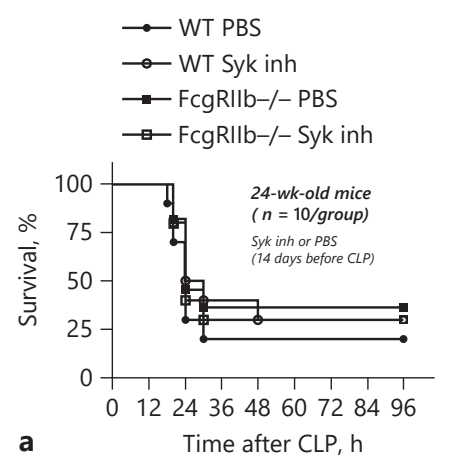

$\square 48$ h pre-CLP $\square 24$ h post-CLP

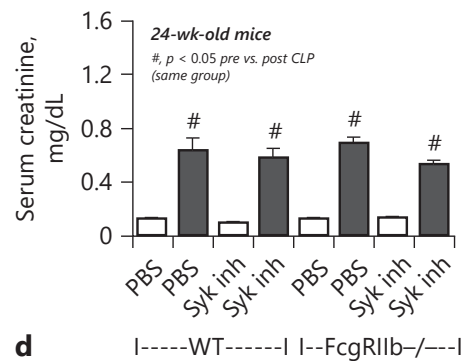

$\square 48$ h pre-CLP $\square 24$ h post-CLP

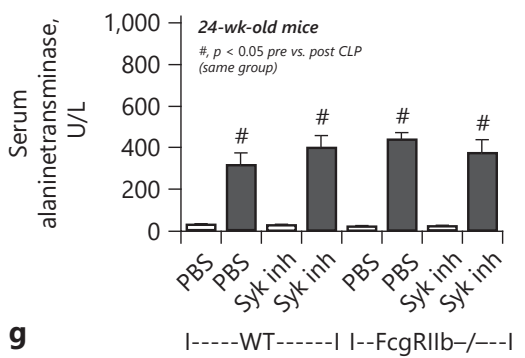

$\square 48$ h pre-CLP $\square 24$ h post-CLP

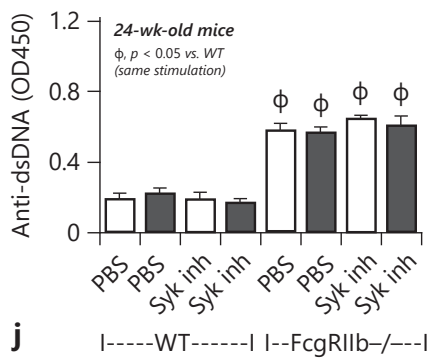

$\longrightarrow$ WT PBS

$\longrightarrow$ WT Syk inh

$\longrightarrow$ FcgRIlb-/- PBS

$\rightarrow-F c g R I l b-/-$ Syk inh

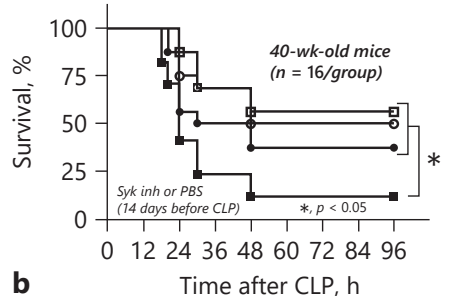

$\square 48$ h pre-CLP $\square 24$ h post-CLP

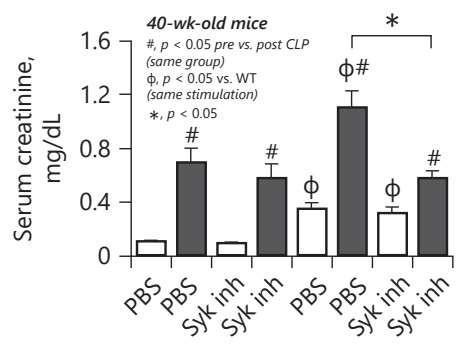

e
FcgRIIb-/-PBS 24 wk ( $n=10)$

$\rightarrow$ FcgRllb-/- PBS_40 wk $(n=16)$

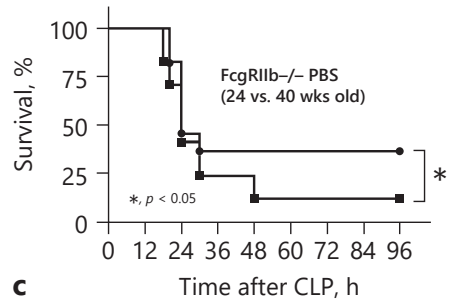

$\square 48$ h pre-CLP

$24 \mathrm{~h}$ post-CLP

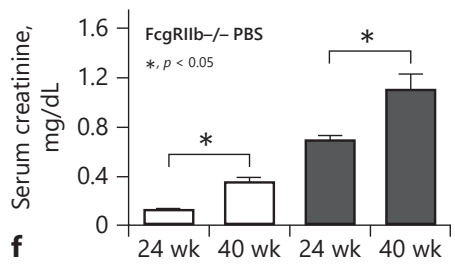

$\square 48$ h pre-CLP

$24 \mathrm{~h}$ post-CLP
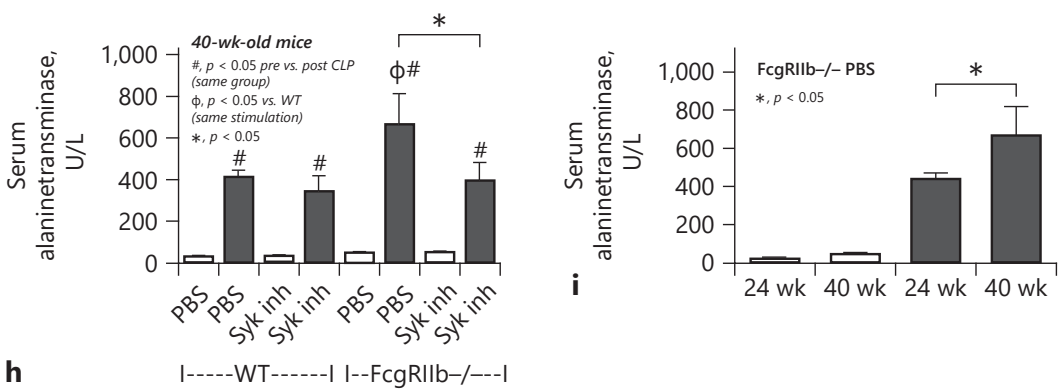

$\square 48 \mathrm{~h}$ pre-CLP $\square 24 \mathrm{~h}$ post-CLP

$\square 48$ h pre-CLP $\square 24$ h post-CLP
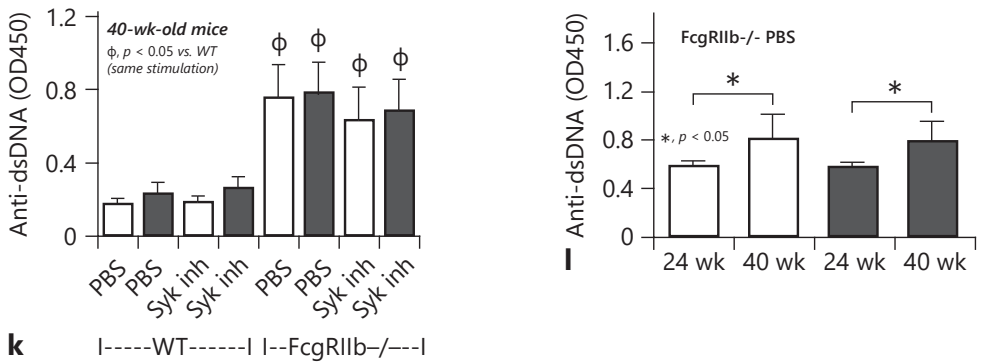

Fig. 7. Sepsis severity after 14 days of Syk inhibitor treatment in sepsis mice. Characteristics of FcgRIIb ${ }^{-/-}$or wildtype (WT) mice aged 24 and 40 weeks before and after cecal ligation and puncture (CLP) surgery and 14 days after Syk inhibitor administration (Syk inh) or PBS control by survival analysis (a-c) $(n=10$ and 16/group for $\mathbf{a}$ and $\mathbf{b}$, respectively), serum creatinine $(\mathbf{d}-\mathbf{f})$, serum alanine transaminase $(\mathbf{g}-\mathbf{i})$, and serum anti-dsDNA antibodies $(\mathbf{j}-\mathbf{I})(n=5-7 /$ group for $\mathbf{d}-\mathbf{I})$. c, $\mathbf{f}, \mathbf{i}$, I show better visualization of the difference in sepsis between FcgRIIb ${ }^{-/-}$ mice aged 24 and 40 weeks. 
Fig. 8. Kidney histology after 14 days of Syk inhibitor treatment in sepsis mice. Representative figures of kidney histology (hematoxylin and eosin staining) of 40-weekold FcgRIIb ${ }^{-1-}$ and wild-type (WT) mice with sham operation or CLP with and without Syk inhibitor (Syk inh) (a) (original magnification $\times 200)$ and tubular injury score (b) ( $n=4-6 /$ group). Data of 24-weekold mice are not shown because there were no differences between Syk-treated and control CLP mice. Arrow head, lupus-induced mesangial glomerulonephritis; arrow, sepsis-induced tubular injury demonstrated by cast formation and tubular cell vacuolization.

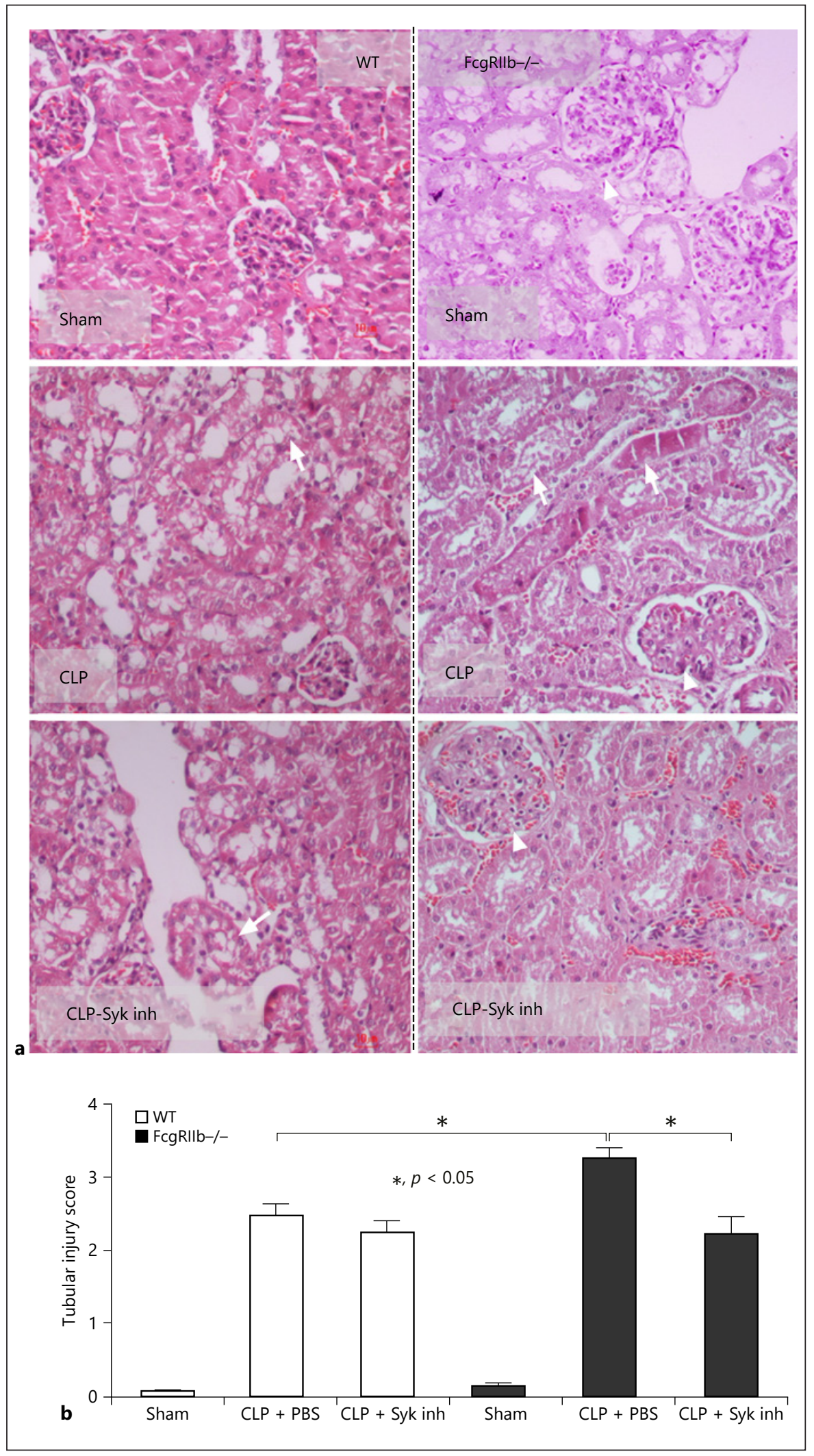

J Innate Immun 2020;12:461-479 


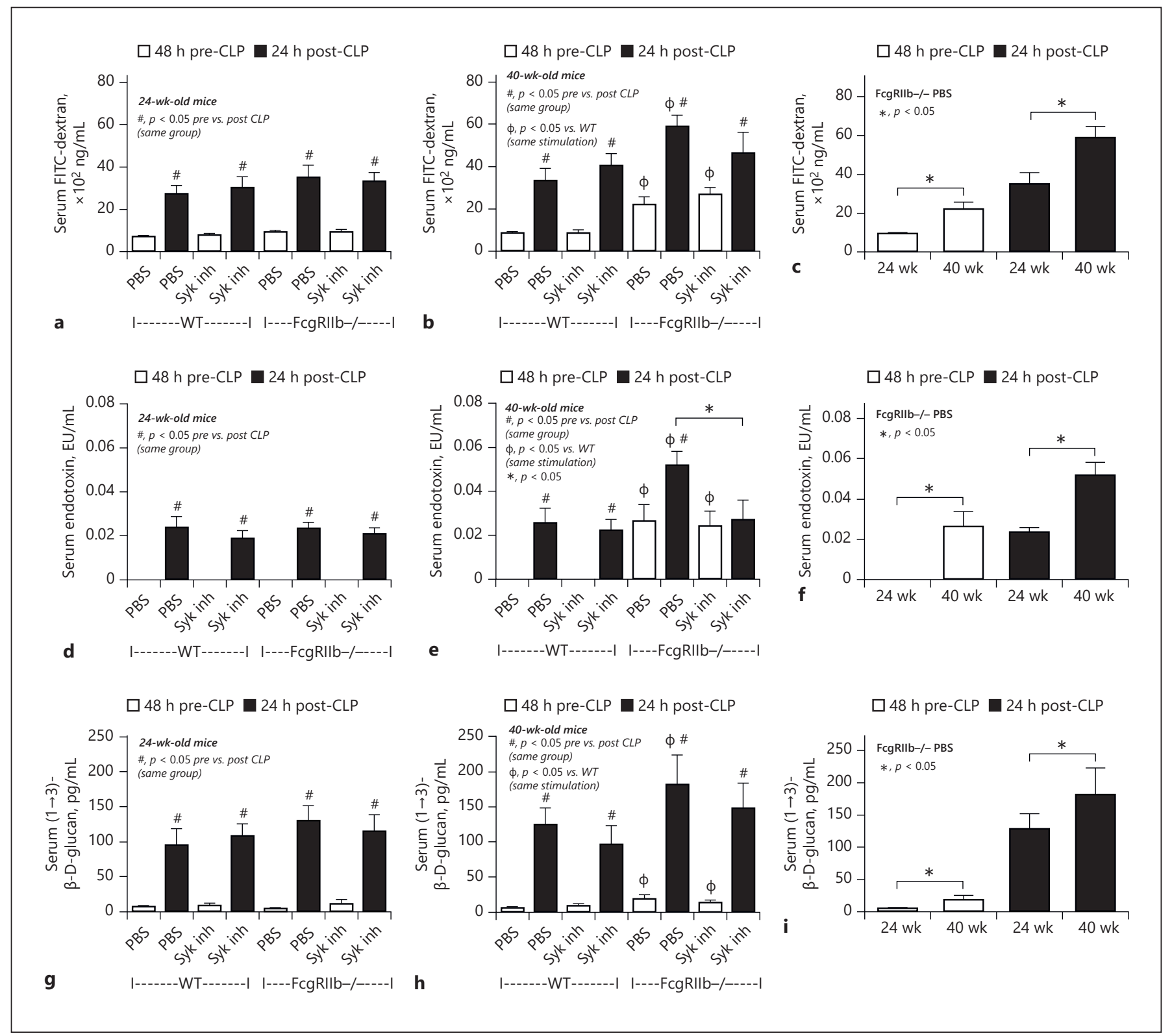

Fig. 9. Gut leakage after 14 days of Syk inhibitor treatment in sepsis mice. Characteristics of FcgRIIb ${ }^{-/-}$or wildtype (WT) mice aged 24 and 40 weeks before and after cecal ligation and puncture (CLP) surgery 14 days after Syk inhibitor administration (Syk inh) or PBS control. Serum FITC-dextran (a-c), serum endotoxin (d-f), and serum $(1 \rightarrow 3)$ - $\beta$-D-glucan (BG) ( $\mathbf{g}$-i) levels ( $n=5-7 /$ group). c, f, i show a better visualization of the difference in sepsis between FcgRIIb ${ }^{-/-}$mice aged 24 and 40 weeks.

by exogenous endotoxin injection without bacteremia) [23], it has not been studied in CLP sepsis model (a model with both bacteremia and endotoxemia) [44]. Interestingly, the 14-day administration but not the 3-day gavage of a Syk inhibitor decreased lupus-induced systemic inflammation at baseline (pre-CLP surgery) and attenuated sepsis severity in 40-week-old FcgRIIb ${ }^{-/-}$mice. In contrast, the Syk inhibitor had a reduced anti-inflammatory effect on sepsis in mice at 24-week-old of both FcgRIIb ${ }^{-/-}$ and WT groups. This might be explained by the lack of gut leakage and/or systemic inflammation at baseline in 24-week-old FcgRIIb ${ }^{-/-}$mice and WT mice (both 24- and 


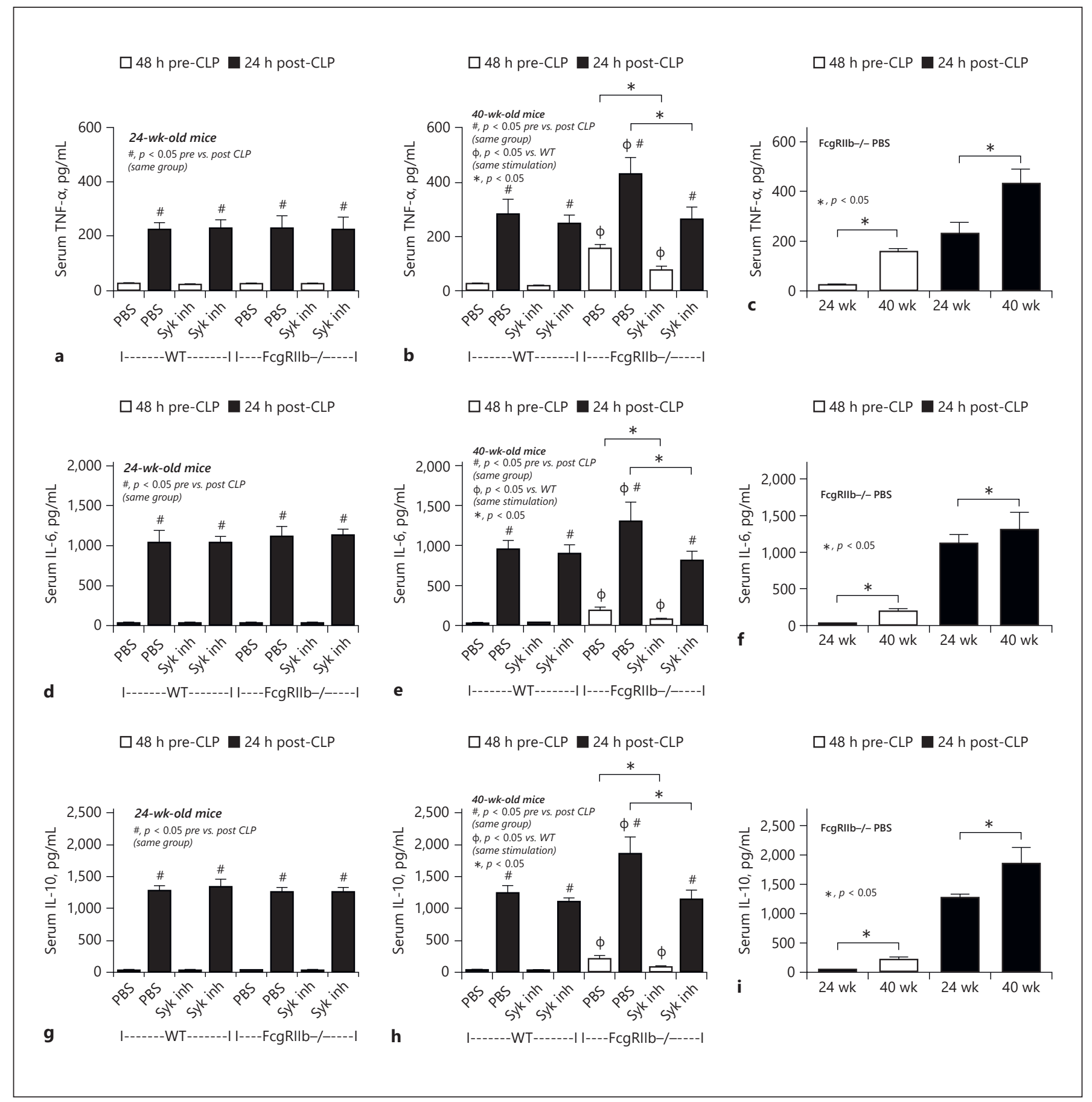

Fig. 10. Systemic inflammation after 14 days of Syk inhibitor treatment in sepsis mice. Levels of systemic cytokines in $\mathrm{FcgRIIb}^{-/-}$or wild-type (WT) mice aged 24 and 40 weeks before and after cecal ligation and puncture (CLP) surgery 14 days after Syk inhibitor administration (Syk inh) or PBS control. Serum TNF-a (a-c), IL-6 (d-f), and IL-10 (g-i) levels ( $n=5-7 /$ group). c, f, i show a better visualization of the difference in sepsis between $\mathrm{FcgRIIb}^{-/-}$mice aged 24 and 40 weeks. 


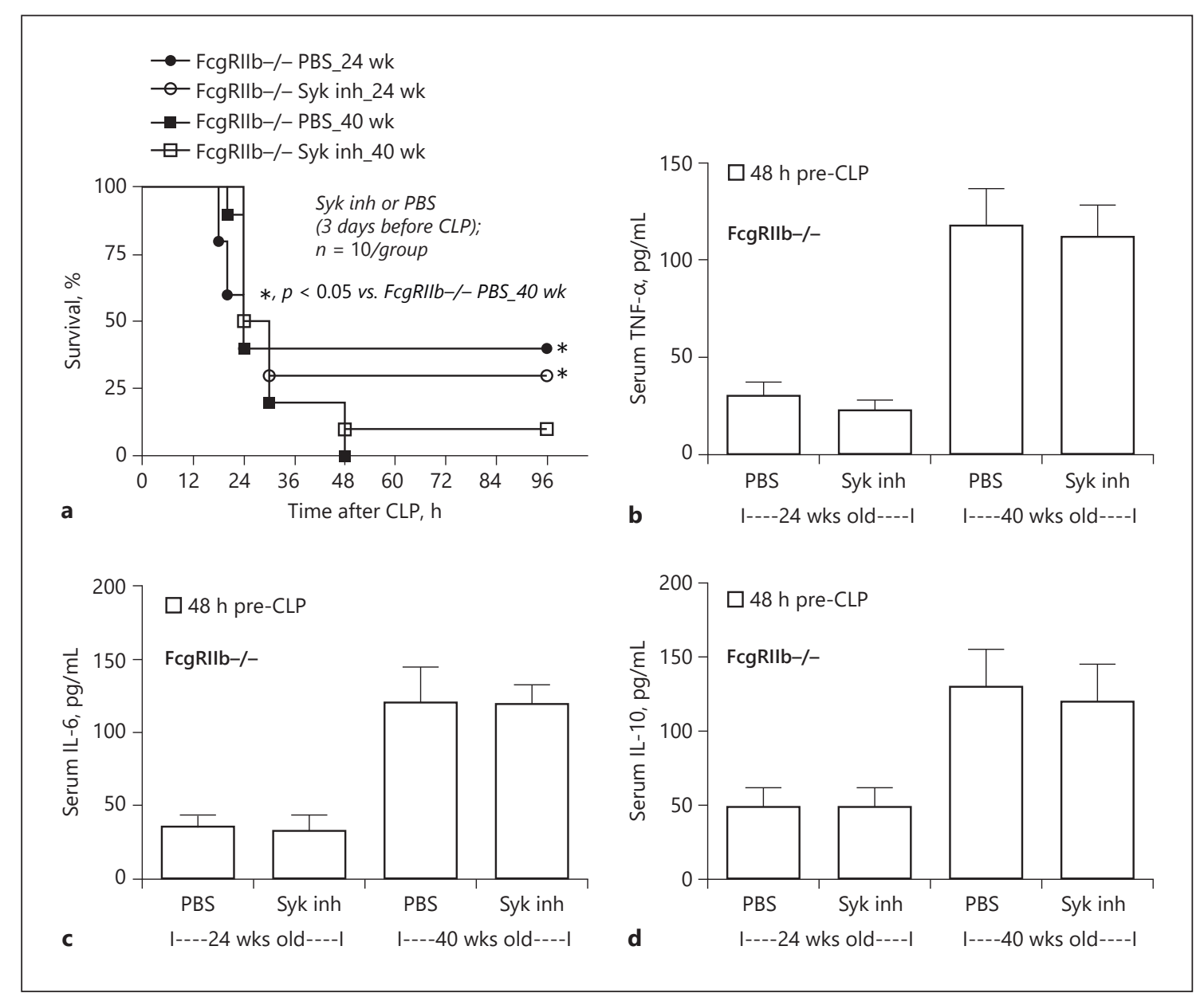

Fig. 11. Sepsis severity after 3 days of Syk inhibitor treatment in sepsis mice. a Survival analysis of FcgRIIb ${ }^{-/-}$mice $^{-10}$ aged 24 and 40 weeks after 3 days of Syk inhibitor administration (Syk inh) or PBS control ( $n=10 /$ group). b-d Systemic inflammation determined by serum cytokines before cecal ligation and puncture (CLP) surgery ( $n=10$ /group).

40-week-old age groups). Despite increased levels of antidsDNA antibodies in 24-week-old FcgRIIb ${ }^{-1-}$ mice, the 14-day administration of the Syk inhibitor did not reduce baseline anti-DNA antibody titers (pre-CLP surgery) or sepsis severity, implying a lesser impact of Syk induction through FcgR, by the activation from immune complex of anti-dsDNA antibodies, upon sepsis severity.

The anti-inflammatory effects of Syk inhibitors might also be related to the blockade of FcgR, dectin-1, and TLR-4, as well as interfering with other proinflammatory pathways. RNA sequencing of WGP + LPS activated macrophages treated with the Syk inhibitor demonstrated reduced gene expressions of proinflammatory pathways, including Akt, MAPK, NOD, and cytosolic DNA. Interestingly, the gene expression in LPS + BG activated
$\mathrm{FcgRIIb}^{-/-}$macrophages was similar to that in a large number of patients with severe sepsis [33], suggesting the potential influence of immune activation by LPS + BG, the representatives of pathogenic molecules, in patients with sepsis. Accordingly, increased serum BG levels were observed in patients with severe bacterial sepsis, even without fungal infection, via sepsis-induced gut leakage with gut translocation of BG [14]. Some of the genes coexpressed by LPS + BG activated macrophages and patients with severe bacterial sepsis are of note. Activation by LPS + BG upregulated DNA damage inducible transcript 4 (DDIT4) and occludin (OCLN), genes responsible for hypoxic responses and epithelial morphological stability, respectively $[45,46]$, and downregulated CX3C chemokine receptor 1 (CXC3CR1), a gene responsible for 
leukocyte migration and monocyte survival [47]. Nevertheless, the Syk inhibitor downregulated DDIT4 and OCLN and upregulated CXC3CR1 in LPS + BG activated macrophages, whereas sepsis was attenuated in 40 -weekold FcgRIIb ${ }^{-1-}$ mice, indicating the benefit of a Syk inhibitor for sepsis treatment.

Regarding potential clinical translation, Syk inhibitors are available for the treatment of several autoimmune diseases including lupus and rheumatoid arthritis [48-51]. Although the therapeutic effect of Syk inhibitors against polymicrobial CLP sepsis was low with the short-term administration, our data suggest that susceptibility against bacterial infection might be lower with a longer duration of treatment with a Syk inhibitor, possibly during the treatment of lupus disease activity. Of note, all current lupus treatments, such as steroids and mycophenolate mofetil, are based upon immunosuppression, which can cause several infectious complications [52]. Considering the effect of Syk inhibitors on lupus progression [48-50] together with our data on the reduction of sepsis severity, Syk inhibitors might be an interesting candidate for the treatment of active lupus in patients with FcgRIIb dysfunction polymorphisms.

In conclusion, marked Syk activation was observed in 40-week-old FcgRIIb ${ }^{--}$mice after sepsis induction by proinflammatory activation that related to endotoxemia and glucanemia. A Syk inhibitor attenuated sepsis severity possibly through the reduction of lupus-induced systemic inflammation in full-blown lupus in 40-week-old $\mathrm{FcgRIIb}^{-/-}$mice. Regarding clinical translation, Syk inhibitors might be an interesting drug for lupus treatment with a counter effect on sepsis. Further studies are warranted.

\section{Acknowledgements}

We thank Edanz Group (www.edanzediting.com/ac) for editing a draft of the manuscript.

\section{Statement of Ethics}

This study gained approval from the Institutional Animal Care and Use Committee of the Faculty of Medicine, Chulalongkorn University, Bangkok, Thailand, and followed the animal care and use protocol of the National Institutes of Health (NIH), USA.

\section{Conflict of Interest Statement}

The authors have no conflicts of interest to disclose.

\section{Funding Sources}

This work was supported by the Thailand Government Fund (RSA6080023 and RES_61_202_30_022) and Ratchadapisek Sompoch (CU_GR_63_108_3 and 76001-HR), J.I.-A. was supported by the International Research Network (IRN), the Thailand Research Fund (IRN59W0004).

\section{Author Contributions}

Conceptualization: A.L.; methodology: J.I.-A, A.L., W.C., and P.V.; investigation: A.L. and W.C.; writing, original draft preparation: A.L. and J.I.-A.; writing, review and editing: A.L., J.I.-A., and W.C.; supervision: A.L.; and funding acquisition: A.L.

\section{References}

1 Bolland S, Ravetch JV. Spontaneous autoimmune disease in $\mathrm{Fc}$ (gamma)RIIB-deficient mice results from strain-specific epistasis. Immunity. 2000 Aug;13(2):277-85.

2 Clatworthy MR, Willcocks L, Urban B, Langhorne J, Williams TN, Peshu N, et al. Systemic lupus erythematosus-associated defects in the inhibitory receptor FcgammaRIIb reduce susceptibility to malaria. Proc Natl Acad Sci U S A. 2007 Apr 24;104(17):7169-74.

3 Crispín JC, Hedrich CM, Tsokos GC. Genefunction studies in systemic lupus erythematosus. Nat Rev Rheumatol. 2013 Aug;9(8): $476-84$.
4 Chu ZT, Tsuchiya N, Kyogoku C, Ohashi J, Qian YP, Xu SB, et al. Association of Fcgamma receptor IIb polymorphism with susceptibility to systemic lupus erythematosus in Chinese: a common susceptibility gene in the Asian populations. Tissue Antigens. 2004 Jan; 63(1):21-7.

5 Shi L, Zhang Z, Yu AM, Wang W, Wei Z, Akhter E, et al. The SLE transcriptome exhibits evidence of chronic endotoxin exposure and has widespread dysregulation of noncoding and coding RNAs. PLoS One. 2014; 9(5):e93846.
6 Issara-Amphorn J, Surawut S, Worasilchai N, Thim-Uam A, Finkelman M, Chindamporn $A$, et al. The synergy of endotoxin and $(1 \rightarrow 3)-\beta$-d-glucan, from gut translocation, worsens sepsis severity in a lupus model of Fc gamma receptor IIb-deficient mice. J Innate Immun. 2018;10(3):189-201.

7 Underhill DM, Iliev ID. The mycobiota: interactions between commensal fungi and the host immune system. Nat Rev Immunol. 2014 Jun;14(6):405-16.

8 Amornphimoltham P, Yuen PST, Star RA, Leelahavanichkul A. Gut leakage of fungalderived inflammatory mediators: part of a gut-liver-kidney axis in bacterial sepsis. Dig Dis Sci. 2019 Sep;64(9):2416-28. 
9 Panpetch W, Hiengrach $P$, Nilgate $S$, Tumwasorn S, Somboonna N, Wilantho A, et al. Additional Candida albicans administration enhances the severity of dextran sulfate solution induced colitis mouse model through leaky gut-enhanced systemic inflammation and gut-dysbiosis but attenuated by Lactobacillus rhamnosus L34. Gut Microbes. 2019 Sep 18; 11(3):465-80.

10 Panpetch W, Somboonna N, Palasuk M, Hiengrach P, Finkelman M, Tumwasorn S, et al. Oral Candida administration in a Clostridium difficile mouse model worsens disease severity but is attenuated by Bifidobacterium. PLoS One. 2019;14(1):e0210798.

11 Engstad CS, Engstad RE, Olsen JO, Osterud B. The effect of soluble beta-1,3-glucan and lipopolysaccharide on cytokine production and coagulation activation in whole blood. Int Immunopharmacol. 2002 Oct;2(11):1585-97.

12 Kikkert R, Bulder I, de Groot ER, Aarden LA, Finkelman MA. Potentiation of toll-like receptor-induced cytokine production by $(1 \rightarrow 3)$-beta-d-glucans: implications for the monocyte activation test. J Endotoxin Res. 2007;13(3):140-9.

13 Ferwerda G, Meyer-Wentrup F, Kullberg BJ, Netea MG, Adema GJ. Dectin-1 synergizes with TLR2 and TLR4 for cytokine production in human primary monocytes and macrophages. Cell Microbiol. 2008 Oct; 10(10): 2058-66.

14 Leelahavanichkul A, Worasilchai N, Wannalerdsakun S, Jutivorakool K, Somparn P, Issara-Amphorn J, et al. Gastrointestinal leakage detected by serum $(1 \rightarrow 3)-\beta$-d-glucan in mouse models and a pilot study in patients with sepsis. Shock. 2016 Nov;46(5):506-18.

15 Ropes MW. Observations on the natural course of disseminated lupus erythematosus. Medicine. 1964 May;43:387-91.

16 Ondee T, Surawut S, Taratummarat S, Hirankarn N, Palaga T, Pisitkun P, et al. Fc Gamma receptor IIB deficient mice: a lupus model with increased endotoxin tolerance-related sepsis susceptibility. Shock. 2017 Jun;47(6): $743-52$.

17 Mócsai A, Ruland J, Tybulewicz VL. The SYK tyrosine kinase: a crucial player in diverse biological functions. Nat Rev Immunol. 2010 Jun;10(6):387-402.

18 Lin YC, Huang DY, Chu CL, Lin YL, Lin WW. The tyrosine kinase syk differentially regulates toll-like receptor signaling downstream of the adaptor molecules TRAF6 and TRAF3. Sci Signal. 2013 Aug 20;6(289):ra71.

19 McKeage K, Lyseng-Williamson KA. Correction to: fostamatinib in chronic immune thrombocytopenia: a profile of its use in the USA. Drugs Ther Perspect. 2018;34(12):594.

20 Smith J, McDaid JP, Bhangal G, Chawanasuntorapoj R, Masuda ES, Cook HT, et al. A spleen tyrosine kinase inhibitor reduces the severity of established glomerulonephritis. J Am Soc Nephrol. 2010 Feb;21(2):231-6.
21 McAdoo SP, Reynolds J, Bhangal G, Smith J, McDaid JP, Tanna A, et al. Spleen tyrosine kinase inhibition attenuates autoantibody production and reverses experimental autoimmune GN. J Am Soc Nephrol. 2014 Oct; 25(10):2291-302.

22 Kitai M, Fukuda N, Ueno $T$, Endo $M$, Maruyama T, Abe M, et al. Effects of a spleen tyrosine kinase inhibitor on progression of the lupus nephritis in mice. J Pharmacol Sci. 2017 May; 134(1):29-36.

23 Al-Harbi NO, Nadeem A, Ahmad SF, Alanazi MM, Aldossari AA, Alasmari F. Amelioration of sepsis-induced acute kidney injury through inhibition of inflammatory cytokines and oxidative stress in dendritic cells and neutrophils respectively in mice: role of spleen tyrosine kinase signaling. Biochimie. 2019 Mar; 158:102-10.

24 Surawut S, Ondee T, Taratummarat S, Palaga $\mathrm{T}$, Pisitkun $\mathrm{P}$, Chindamporn A, et al. The role of macrophages in the susceptibility of $\mathrm{FC}$ gamma receptor IIb deficient mice to Cryptococcus neoformans. Sci Rep. 2017 Jan 11;7: 40006.

25 Surawut S, Makjaroen J, Thim-Uam A, Wongphoom J, Palaga T, Pisitkun P, et al. Increased susceptibility against Cryptococcus neoformans of lupus mouse models (pristane-induction and FcGRIIb deficiency) is associated with activated macrophage, regardless of genetic background. J Microbiol. 2019 Jan;57(1):45-53.

26 Mihara M, Tan I, Chuzhin Y, Reddy B, Budhai L, Holzer A, et al. CTLA4Ig inhibits T celldependent $\mathrm{B}$-cell maturation in murine systemic lupus erythematosus. J Clin Invest. $2000 \mathrm{Jul} ; 106(1): 91-101$.

27 Leelahavanichkul A, Yan Q, Hu X, Eisner C, Huang Y, Chen R, et al. Angiotensin II overcomes strain-dependent resistance of rapid CKD progression in a new remnant kidney mouse model. Kidney Int. 2010 Dec;78(11): 1136-53.

28 Leelahavanichkul A, Huang Y, Hu X, Zhou H, Tsuji T, Chen R, et al. Chronic kidney disease worsens sepsis and sepsis-induced acute kidney injury by releasing high mobility group box protein-1. Kidney Int. 2011 Dec;80(11): 1198-211.

29 Ondee T, Jaroonwitchawan T, Pisitkun T, Gillen J, Nita-Lazar A, Leelahavanichkul A, et al. Decreased protein kinase C- $\beta$ type II associated with the prominent endotoxin exhaustion in the macrophage of FcGRIIb-/- lupus prone mice is revealed by phosphoproteomic analysis. Int J Mol Sci. 2019 Mar 18;20(6): 1354.

30 Ondee T, Gillen J, Visitchanakun P, Somparn $\mathrm{P}$, Issara-Amphorn J, Dang Phi C, et al. Lipocalin-2 (Lcn-2) attenuates polymicrobial sepsis with LPS preconditioning (LPS tolerance) in FcGRIIb deficient lupus mice. Cells. 2019 Sep 11;8(9):1064.
31 Taratummarat S, Sangphech N, Vu CTB, Palaga $\mathrm{T}$, Ondee $\mathrm{T}$, Surawut $\mathrm{S}$, et al. Gold nanoparticles attenuates bacterial sepsis in cecal ligation and puncture mouse model through the induction of M2 macrophage polarization. BMC Microbiol. 2018 Aug 17; 18(1):85.

32 Dennehy KM, Ferwerda G, Faro-Trindade I, Pyz E, Willment JA, Taylor PR, et al. Syk kinase is required for collaborative cytokine production induced through dectin-1 and toll-like receptors. Eur J Immunol. $2008 \mathrm{Feb}$; 38(2):500-6.

33 Sweeney TE, Perumal TM, Henao R, Nichols M, Howrylak JA, Choi AM, et al. A community approach to mortality prediction in sepsis via gene expression analysis. Nat Commun. 2018 Feb 15;9(1):694.

34 Yi YS, Son YJ, Ryou C, Sung GH, Kim JH, Cho JY. Functional roles of Syk in macrophagemediated inflammatory responses. Mediators Inflamm. 2014;2014:270302.

35 Hossain MK, Wall KA. Use of dendritic cell receptors as targets for enhancing anti-cancer immune responses. Cancers. 2019 Mar 24; 11(3):418.

36 Doi K, Leelahavanichkul A, Hu X, Sidransky KL, Zhou H, Qin Y, et al. Pre-existing renal disease promotes sepsis-induced acute kidney injury and worsens outcome. Kidney Int. 2008 Oct;74(8):1017-25.

37 Panpetch W, Somboonna N, Bulan DE, Issara-Amphorn J, Finkelman M, Worasilchai $\mathrm{N}$, et al. Oral administration of live- or heatkilled Candida albicans worsened cecal ligation and puncture sepsis in a murine model possibly due to an increased serum $(1 \rightarrow 3)-\beta$-dglucan. PLoS One. 2017;12(7):e0181439.

38 Wang HE, Shapiro NI, Griffin R, Safford MM, Judd S, Howard G. Chronic medical conditions and risk of sepsis. PLoS One. 2012;7(10): e48307.

39 Yende S, Iwashyna TJ, Angus DC. Interplay between sepsis and chronic health. Trends Mol Med. 2014 Apr;20(4):234-8.

40 Mira JC, Gentile LF, Mathias BJ, Efron PA, Brakenridge SC, Mohr AM, et al. Sepsis pathophysiology, chronic critical illness, and persistent inflammation-immunosuppression and catabolism syndrome. Crit Care Med. 2017 Feb;45(2):253-62.

41 Muenzer JT, Davis CG, Dunne BS, Unsinger J, Dunne WM, Hotchkiss RS. Pneumonia after cecal ligation and puncture: a clinically relevant "two-hit" model of sepsis. Shock. 2006 Dec;26(6):565-70.

42 D Restagno J-MB, Kodjo A, Venet F, Paquet C, Freyburger L, Louzier V. Mice survival in a two-hit model of sepsis depends on intratracheal P. aeruginosa bacterial load. Critial Care. 2014;18:59.

43 Osuchowski MF, Remick DG, Lederer JA, Lang CH, Aasen AO, Aibiki M, et al. Abandon the mouse research ship? Not just yet! Shock. 2014 Jun;41(6):463-75. 
44 Doi K, Leelahavanichkul A, Yuen PS, Star RA. Animal models of sepsis and sepsis-induced kidney injury. J Clin Invest. 2009 Oct;119(10): 2868-78.

45 Saitou M, Furuse M, Sasaki H, Schulzke JD, Fromm M, Takano H, et al. Complex phenotype of mice lacking occludin, a component of tight junction strands. Mol Biol Cell. 2000 Dec;11(12):4131-42.

46 Shoshani T, Faerman A, Mett I, Zelin E, Tenne T, Gorodin S, et al. Identification of a novel hypoxia-inducible factor 1-responsive gene, RTP801, involved in apoptosis. Mol Cell Biol. 2002 Apr;22(7):2283-93.
47 Landsman L, Bar-On L, Zernecke A, Kim KW, Krauthgamer R, Shagdarsuren E, et al. CX3CR1 is required for monocyte homeostasis and atherogenesis by promoting cell survival. Blood. 2009 Jan 22;113(4):963-72.

48 Bahjat FR, Pine PR, Reitsma A, Cassafer G, Baluom M, Grillo S, et al. An orally bioavailable spleen tyrosine kinase inhibitor delays disease progression and prolongs survival in murine lupus. Arthritis Rheum. 2008 May; 58(5):1433-44.

49 Weinblatt ME, Kavanaugh A, Burgos-Vargas R, Dikranian AH, Medrano-Ramirez G, Morales-Torres JL, et al. Treatment of rheumatoid arthritis with a Syk kinase inhibitor: a twelve-week, randomized, placebo-controlled trial. Arthritis Rheum. 2008 Nov; 58(11):3309-18.
50 Deng GM, Liu L, Bahjat FR, Pine PR, Tsokos GC. Suppression of skin and kidney disease by inhibition of spleen tyrosine kinase in lupus-prone mice. Arthritis Rheum. 2010 Jul; 62(7):2086-92.

51 Ozaki N, Suzuki S, Ishida M, Harada Y, Tanaka K, Sato Y, et al. Syk-dependent signaling pathways in neutrophils and macrophages are indispensable in the pathogenesis of anti-collagen antibody-induced arthritis. Int Immunol. 2012 Sep;24(9):539-50.

52 Torres-Ruiz J, Mejía-Domínguez NR, Zentella-Dehesa A, Ponce-de-León A, Morales-Padilla SR, Vázquez-Rodríguez R, et al. The systemic lupus erythematosus infection predictive index (LIPI): a clinical-immunological tool to predict infections in lupus patients. Front Immunol. 2018;9:3144. 